\title{
Modelling the formation and composition of secondary organic aerosol from $\alpha$ - and $\beta$-pinene ozonolysis using MCM v3
}

\author{
M. E. Jenkin \\ Dept. of Environmental Science and Technology, Imperial College London, Silwood Park, Ascot, Berkshire, SL5 7PY, UK \\ Received: 13 April 2004 - Published in Atmos. Chem. Phys. Discuss.: 28 May 2004 \\ Revised: 10 August 2004 - Accepted: 17 August 2004 - Published: 3 September 2004
}

\begin{abstract}
The formation and detailed composition of secondary organic aerosol (SOA) from the gas phase ozonolysis of $\alpha$ - and $\beta$-pinene has been simulated using the Master Chemical Mechanism version 3 (MCM v3), coupled with a representation of gas-to-aerosol transfer of semivolatile and involatile oxygenated products. A kinetics representation, based on equilibrium absorptive partitioning of ca. 200 semivolatile products, was found to provide an acceptable description of the final mass concentrations observed in a number of reported laboratory and chamber experiments, provided partitioning coefficients were increased by about two orders of magnitude over those defined on the basis of estimated vapour pressures. This adjustment is believed to be due, at least partially, to the effect of condensed phase association reactions of the partitioning products. Even with this adjustment, the simulated initial formation of SOA was delayed relative to that observed, implying the requirement for the formation of species of much lower volatility to initiate SOA formation. The inclusion of a simplified representation of the formation and gas-to-aerosol transfer of involatile dimers of 22 bi- and multifunctional carboxylic acids (in addition to the absorptive partitioning mechanism) allowed a much improved description of SOA formation for a wide range of conditions. The simulated SOA composition recreates certain features of the product distributions observed in a number of experimental studies, but implies an important role for multifunctional products containing hydroperoxy groups (i.e. hydroperoxides). This is particularly the case for experiments in which 2-butanol is used to scavenge $\mathrm{OH}$ radicals, because $\left[\mathrm{HO}_{2}\right] /\left[\mathrm{RO}_{2}\right]$ ratios are elevated in such systems. The optimized mechanism is used to calculate SOA yields from $\alpha$ - and $\beta$-pinene ozonolysis in the presence and absence of $\mathrm{OH}$ scavengers, and as a function of temperature.
\end{abstract}

$\overline{\text { Correspondence to: } \mathrm{M} .} \mathrm{E}$. Jenkin

(m.jenkin@imperial.ac.uk)

\section{Introduction}

It is well documented that the oxidation of monoterpenes in the troposphere plays an important role in the generation of ozone, $\mathrm{O}_{3}$, and secondary organic aerosols, SOA (e.g. Went, 1960; Rasmussen, 1972; Trainer et al., 1987; Jacob and Wofsy, 1988; Andreae and Crutzen, 1997), and particular attention has therefore been given to elucidating the oxidation mechanisms of monoterpenes known to be emitted into the troposphere in substantial quantities (e.g. Calogirou et al., 1999; Atkinson and Arey, 2003). Much emphasis has been placed on $\alpha$ - and $\beta$-pinene, since measurements of monoterpene speciation suggest that these make a particularly significant contribution to global monoterpene emissions (e.g. Guenther et al., 1994; Fuentes et al., 2000; Geron et al., 2000), and also because they are representative of classes of monoterpene having either an endocyclic double bond (in the case of $\alpha$-pinene) or an exocyclic double bond (in the case of $\beta$-pinene). As a result, particular progress has been made in establishing the kinetics and products of the early stages of the oxidation, initiated by the reactions with $\mathrm{OH}$ radicals, $\mathrm{NO}_{3}$ radicals and $\mathrm{O}_{3}$ (e.g. Atkinson and Arey, 2003, and references therein).

The ability of $\alpha$-and $\beta$-pinene (and other monoterpenes) to generate condensable material, and therefore SOA, has received increasing attention in recent years, and there is a growing body of information on SOA formation and composition, both in the laboratory and the troposphere. Laboratory and chamber studies have demonstrated that aerosol yields are very variable, depending on the identity and starting concentration of the terpene, on the experimental conditions, and on whether oxidation is initiated predominantly by reaction with $\mathrm{O}_{3}, \mathrm{OH}$ or $\mathrm{NO}_{3}$ (e.g. Hoffmann et al., 1997; BIOVOC, 1998; Hallquist et al., 1999; Griffin et al., 1999; Koch et al., 1999; Bonn and Moortgat, 2002; Docherty and Ziemann, 2003). In particular, the reported studies have indicated that dark ozonolysis experiments tend to lead to the largest aerosol yields, and that the fractional yields in all 
experiments generally depend on the organic aerosol mass concentration. Studies of the composition of SOA generated from the ozonolysis of $\alpha$ - and $\beta$-pinene (e.g. Yu et al., 1999a; Jang and Kamens, 1999; Glasius et al., 2000; Kückelmann et al., 2001; Warscheid and Hoffmann, 2001; 2002; Jaoui and Kamens, 2003; Winterhalter et al., 2003) have established that important contributions are made by bi- and multifunctional carboxylic acids, such as pinic acid and pinonic acid, although a number of other oxidized products not containing acid groups have also been detected in the aerosol phase. The carboxylic acids have been suggested as key species in the nucleation of new aerosols in chamber systems (Christoffersen et al., 1998; Koch et al., 1999), and evidence for mechanisms involving homomolecular and heteromolecular acid dimers has been reported (Hoffmann et al., 1998; Kückelmann et al., 2001).

A number of $\alpha$ - and $\beta$-pinene oxidation products have also been detected and quantified in field studies of aerosol composition in forested locations, providing direct evidence for SOA formation from monoterpene oxidation under tropospheric conditions. Kavouras et al. $(1998,1999)$ and Yu et al. (1999b) observed significant contributions to fine particles from pinic acid, pinonic acid, norpinonic acid (and isomers), pinonaldehyde and nopinone at locations in Portugal, Canada and the USA, and quantified the partitioning of these species between the gaseous and condensed phases. More recently, O'Dowd et al. (2002) reported evidence that newly formed particles (3-5 nm diameter) over the boreal forest in Finland were composed mainly of species such as pinonic acid and pinic acid, and proposed that the nucleation of new aerosols was driven by the generation of such products from monoterpene oxidation.

The results of chamber investigations of SOA formation from $\alpha$ - and $\beta$-pinene ozonolysis have commonly been interpreted or modelled in terms of absorptive gas-aerosol partitioning of semivolatile oxidation products. This has involved either the assignment of empirically-derived yields and partitioning coefficients to two notional products (e.g. Hoffmann et al., 1997; Yu et al., 1999a; Cocker et al., 2001), or the consideration of the partitioning of a series of known products, with partitioning coefficients based on estimated properties (Kamens et al., 1999) or on experimentally measured concentrations in the gaseous and condensed phases (Yu et al., 1999a; Cocker et al., 2001). In the present paper, the development, optimization and application of a highly detailed chemical description of SOA formation from the ozonolysis of $\alpha$ - and $\beta$-pinene is described. The methodology is based on the near-explicit Master Chemical Mechanism version 3 (MCM v3) to describe the gas phase chemistry, coupled with a representation of gas-to-aerosol transfer of ca. 200 semivolatile and involatile oxygenated products. The simulated major components of SOA are compared with those reported in a number of experimental studies, and the impacts of different experimental conditions on SOA yields are explored.

\section{Mechanism construction}

\subsection{Gas phase degradation}

The description of the degradation of $\alpha$ - and $\beta$-pinene was taken from the Master Chemical Mechanism, version 3 (MCM v3). The entire mechanism treats the degradation of $125 \mathrm{VOC}$, and can be accessed from the MCM website at http://mcm.leeds.ac.uk/MCM/.

The mechanism was constructed to represent the complete gas-phase degradation of the VOC through to $\mathrm{CO}_{2}$ and $\mathrm{H}_{2} \mathrm{O}$. MCM v3 generally takes account of reported kinetic and mechanistic information available up to the beginning of 2001. Although MCM v3 has recently been superseded by v3.1, the chemistry for $\alpha$ - and $\beta$-pinene remains unchanged.

The mechanism construction methodology for $\alpha$ - and $\beta$ pinene has been summarised by Saunders et al. (2003). In each case, the degradation is initiated by reaction with $\mathrm{OH}$, $\mathrm{O}_{3}$ and $\mathrm{NO}_{3}$, and aims to represent reported experimental information which was available for the kinetics and mechanisms of the early stages of the degradation (e.g. Hakola et al., 1994; Glasius et al., 1997; Hallquist et al., 1997; Wangberg et al., 1997; Aschmann et al., 1998; Alvarado et al., 1998a,b; Noziere et al., 1999a, b; Winterhalter et al., 2000; Orlando et al., 2000). The remainder of the chemistry was defined by analogy with the known chemistry for simpler hydrocarbons, as described by Saunders et al. (2003) and Jenkin et al. (1997). The complete scheme degrading $\alpha$ - and $\beta$-pinene through to $\mathrm{CO}_{2}$ and $\mathrm{H}_{2} \mathrm{O}$ contains approximately 1550 reactions of 520 species, and can be obtained in its entirety using the subset mechanism assembling facility, available as part of the MCM website.

The current paper is concerned primarily with the dark chemistry initiated by the reactions with $\mathrm{O}_{3}$. The salient features of aspects of the ozonolysis chemistry, as represented in MCM v3, have been described in some detail by Jenkin et al. (2000). Briefly, the mechanism proceeds in each case via addition of $\mathrm{O}_{3}$ to the double bond, leading initially to formation of energy rich ozonides. These ozonides each decompose rapidly by two possible channels to form Criegee biradicals which also possess excess energy. The energy rich Criegee biradicals are assumed to be either collisionally stabilized, or to decompose to yield $\mathrm{OH}$ and an additional organic radical, with the relative importance of these reactions based, where possible, on literature data (Jenkin et al., 2000; Saunders et al., 2003). The subsequent reactions of the stabilized Criegee biradicals and the organic radicals generated in conjunction with $\mathrm{OH}$, lead to a variety of simple and complex organic products. These may contain a number of functionalities, including acid, peracid, carbonyl, hydroxy and hydroperoxy groups, or combinations of two or more of these. As indicated above, bi- or multifunctional organic acids are of particular interest and relevance to SOA formation. Accordingly, Fig. 1 presents a partial schematic which describes how the formation of the known first generation 


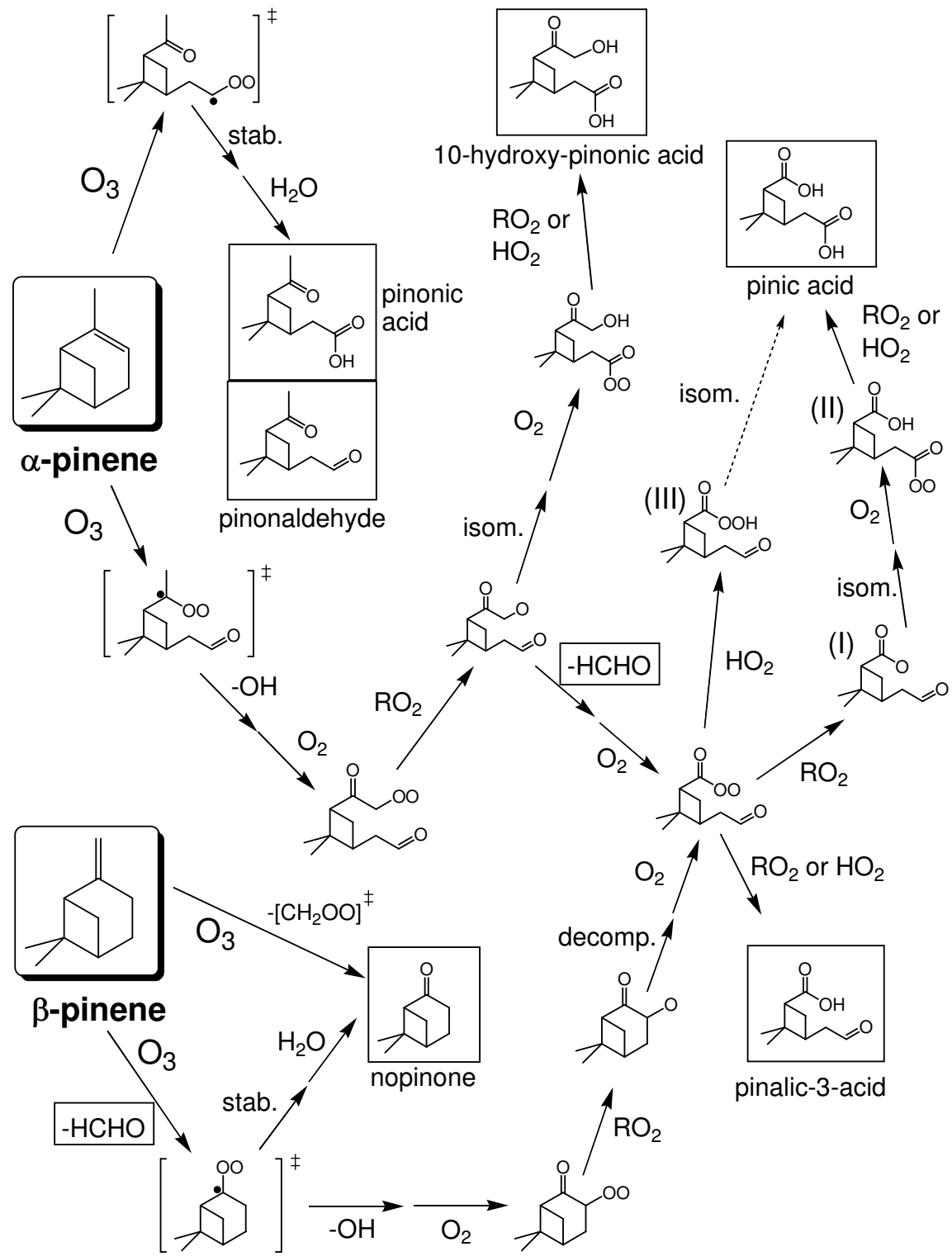

Fig. 1. Schematic representation of the formation routes of $\mathrm{C}_{9}$ and $\mathrm{C}_{10}$ acid products and the major carbonyl products (HCHO, pinonaldehyde and nopinone), following the ozonolysis of $\alpha$ - and $\beta$-pinene, as applied in the present work. The stable products are shown in boxes.

ozonolysis products, pinonic acid, 10-hydroxypinonic acid, pinalic-3-acid and pinic acid is represented in MCM v3. The "permutation" reactions of intermediate peroxy radicals with the available peroxy radical pool $\left(\mathrm{RO}_{2}\right)$ play a key role in the propagation of these mechanisms, and it is the variety of competitive product channels for the various reactions of these peroxy radicals (not all shown in the figure) which largely accounts for the generation of the variety of product classes indicated above. Figure 1 also shows the ozonolysis formation routes for the major carbonyl products, pinonaldehyde, nopinone and formaldehyde. As described by Jenkin et al. (2000), acetone is also produced as a first generation ozonolysis product in this mechanism, via competitive reaction channels not specifically illustrated in the figure.
The formation mechanism for pinic acid has previously been the subject of some discussion (e.g. Jang and Kamens, 1999; Winterhalter et al., 2000; Jenkin et al., 2000). As illustrated in Fig. 1, the primary formation route in MCM v3 follows that postulated by Jenkin et al. (2000), involving the isomerisation of a $\mathrm{C}_{9}$ acyloxy radical intermediate (I), which may be formed from the ozonolysis of both $\alpha$ - and $\beta$-pinene, followed by reaction of the subsequently-formed acyl peroxy radical (II) with either $\mathrm{RO}_{2}$ or $\mathrm{HO}_{2}$. In the present work, pinic acid formation was also supplemented by the closely related mechanism suggested by Winterhalter (2000), involving the intramolecular rearrangement of perpinalic acid (III), generated from the reaction of the corresponding $\mathrm{C}_{9}$ acylperoxy radical with $\mathrm{HO}_{2}$ (see Fig. 1). However, this route tends 
to make only minor contributions to the simulated formation of pinic acid at the $\left[\mathrm{HO}_{2}\right] /\left[\mathrm{RO}_{2}\right]$ ratios of the experiments considered in the present study (see below) .

The ozonolysis of $\alpha$ - and $\beta$-pinene leads to significant generation of $\mathrm{OH}$ radicals. As described by Saunders et al. (2003), the representations in MCM v3, based in part on the structure-reactivity method proposed by Rickard et al. (1999), lead to overall fractional yields of $80 \%$ and $35 \%$, respectively which are consistent with reported experimental studies (Atkinson et al., 1992; Chew and Atkinson, 1996; Paulson et al., 1998, Rickard et al., 1999). In the absence of an added scavenger, dominant reaction of $\mathrm{OH}$ with the parent monoterpene occurs, and the main features of this chemistry under $\mathrm{NO}_{\mathrm{x}}$-free conditions (as represented in MCM v3) are shown in Fig. 2. This provides the possibility of formation of a number of products which are not generated directly from the ozonolysis chemistry (e.g. $\mathrm{C}_{10}$ diols). In some of the experimental studies considered here (e.g. Yu et al., 1999a; Winterhalter et al., 2000), either cyclohexane or 2-butanol was included in the reagent mixture at a sufficient concentration to ensure minimal reaction of $\mathrm{OH}$ with the parent monoterpene. The representation of this chemistry in the present work was also based on that in MCM v3. In the case of cyclohexane, this leads to the exclusive generation of cyclohexylperoxy radicals,

$\mathrm{OH}+c-\mathrm{C}_{6} \mathrm{H}_{12} \rightarrow c-\mathrm{C}_{6} \mathrm{H}_{11}+\mathrm{H}_{2} \mathrm{O}$

$c-\mathrm{C}_{6} \mathrm{H}_{11}+\mathrm{O}_{2}(+\mathrm{M}) \rightarrow c-\mathrm{C}_{6} \mathrm{H}_{11} \mathrm{O}_{2}(+\mathrm{M})$,

which contribute to the pool of $\mathrm{RO}_{2}$ radicals in the system. In the case of 2-butanol, the major oxidation route, accounting for $64 \%$ of the reaction in MCM v3 (consistent with the experimental studies of Chew and Atkinson, 1996; and Baxley and Wells, 1998), leads to the formation of $\mathrm{HO}_{2}$ radicals and 2-butanone,

$$
\begin{aligned}
& \mathrm{OH}+\mathrm{CH}_{3} \mathrm{CH}(\mathrm{OH}) \mathrm{C}_{2} \mathrm{H}_{5} \rightarrow \mathrm{CH}_{3} \mathrm{C}(\mathrm{OH}) \mathrm{C}_{2} \mathrm{H}_{5}+\mathrm{H}_{2} \mathrm{O}( \\
& \mathrm{CH}_{3} \mathrm{C}(\mathrm{OH}) \mathrm{C}_{2} \mathrm{H}_{5}+\mathrm{O}_{2} \rightarrow \mathrm{CH}_{3} \mathrm{C}(\mathrm{O}) \mathrm{C}_{2} \mathrm{H}_{5}+\mathrm{HO}_{2}
\end{aligned}
$$

with the balance of the reaction generating hydroxysubstituted alkylperoxy radicals which contribute to the $\mathrm{RO}_{2}$ radical pool. As a result, cyclohexane and 2-butanol have different influences on the peroxy radical population (in particular $\left.\left[\mathrm{HO}_{2}\right] /\left[\mathrm{RO}_{2}\right]\right)$ when used as $\mathrm{OH}$ radical scavengers, which have a secondary influence on the product distribution from the ozonolysis of the terpene, and therefore on SOA formation (see also, Bonn et al., 2002; Docherty and Ziemann, 2003). However, the products of 2-butanol and cyclohexane oxidation are themselves assumed to have no direct influence on SOA formation.

\subsection{Gas-to-aerosol conversion}

Gas-aerosol partitioning reactions were incorporated into the mechanism for ca. 280 products of $\alpha$ - and $\beta$-pinene oxidation deemed to be potentially semi-volatile, using the criterion that their boiling points are estimated to be $>450 \mathrm{~K}$ (see below). Of these, about 200 are potentially generated under the $\mathrm{NO}_{\mathrm{x}}$-free conditions relevant to the present study. The primary mechanism by which gas-aerosol partitioning is represented is based on the Pankow absorption model (Pankow, 1994), which has been widely used to interpret yields of organic aerosol in chamber studies (e.g. Odum et al., 1996; Hoffmann et al., 1997; Yu et al., 1999a; Cocker et al., 2001). According to this theory, the partitioning of a given organic species between the gaseous and condensed organic phases may be described in terms of an equilibrium partitioning coefficient, $K_{p}$, which is defined as follows,

$K_{p}=\frac{7.501 \times 10^{-9} R T}{\mathrm{MW}_{\mathrm{om}} \zeta p_{L}^{\circ}}$

where $R$ is the ideal gas constant $\left(8.314 \mathrm{~J} \mathrm{~K}^{-1} \mathrm{~mol}^{-1}\right), T$ is temperature $(\mathrm{K}), \mathrm{MW}_{\mathrm{om}}$ is the mean molecular weight of the condensed organic material $\left(\mathrm{g} \mathrm{mol}^{-1}\right), \zeta$ is the activity coefficient of the given species in the condensed organic phase, and $p_{L}^{\circ}$ is its (probably sub-cooled) liquid vapour pressure (Torr). The numerical constant in the numerator is consistent with units of $\mathrm{m}^{3} \mu \mathrm{g}^{-1}$ for $K_{p}$. As discussed by a number of authors (e.g. Pankow, 1994; Kamens et al., 1999), it is not unreasonable to assume that $\zeta$ is unity for a given oxidation product in an aerosol droplet composed of a mixture of similar species, and this assumption is also adopted in the present work.

A fundamental assumption in this approach is that the aerosol possesses an amorphous, liquid-like character (Pankow, 1994), even though many (if not all) the components are likely to be solid at ambient temperatures in their pure states. A key parameter in the calculation is therefore the sub-cooled liquid vapour pressure. The applied values of $p_{L}^{\circ}$ were estimated from boiling points $\left(T_{b}\right)$ and vaporisation entropy changes at $T_{b}\left(\Delta \mathrm{S}_{\mathrm{vap}}\left(T_{b}\right)\right)$ for each of the products, using an expanded, semi-empirical form of the ClausiusClapeyron equation (Baum, 1998), in a similar manner to that described by Kamens et al. (1999):

$\ln \frac{p_{L}^{\circ}}{760}=\frac{-\Delta S_{\mathrm{vap}}\left(T_{b}\right)}{R}\left[1.8\left(\frac{T_{b}}{T}-1\right)-0.8\left(\ln \frac{T_{b}}{T}\right)\right]$.

$T_{b}$ values were estimated using the fragmentation method of Joback and Reid (1987), as modified and extended by Stein and Brown (1994). Values of $\Delta S_{\text {vap }}\left(T_{b}\right)$ were determined from the Kistiakowsky equation with Vetere correction factors appropriate for polar hydrocarbons (e.g. Baum, 1998), although the resultant values were all within $10 \%$ of the species-independent value of ca. $10.5 R\left(\approx 87 \mathrm{~J} \mathrm{~mol}^{-1}\right.$ $\mathrm{K}^{-1}$ ) as defined by Trouton's rule. The values of $K_{p}$ determined in this way generally show a logical progression, reflecting differences in molecular size and the abundance of polar functionalities, as demonstrated for selected $\alpha$ - and $\beta$ pinene products in Table 1. Although not required for the above calculation of $K_{p}$, estimates were also made of solid 


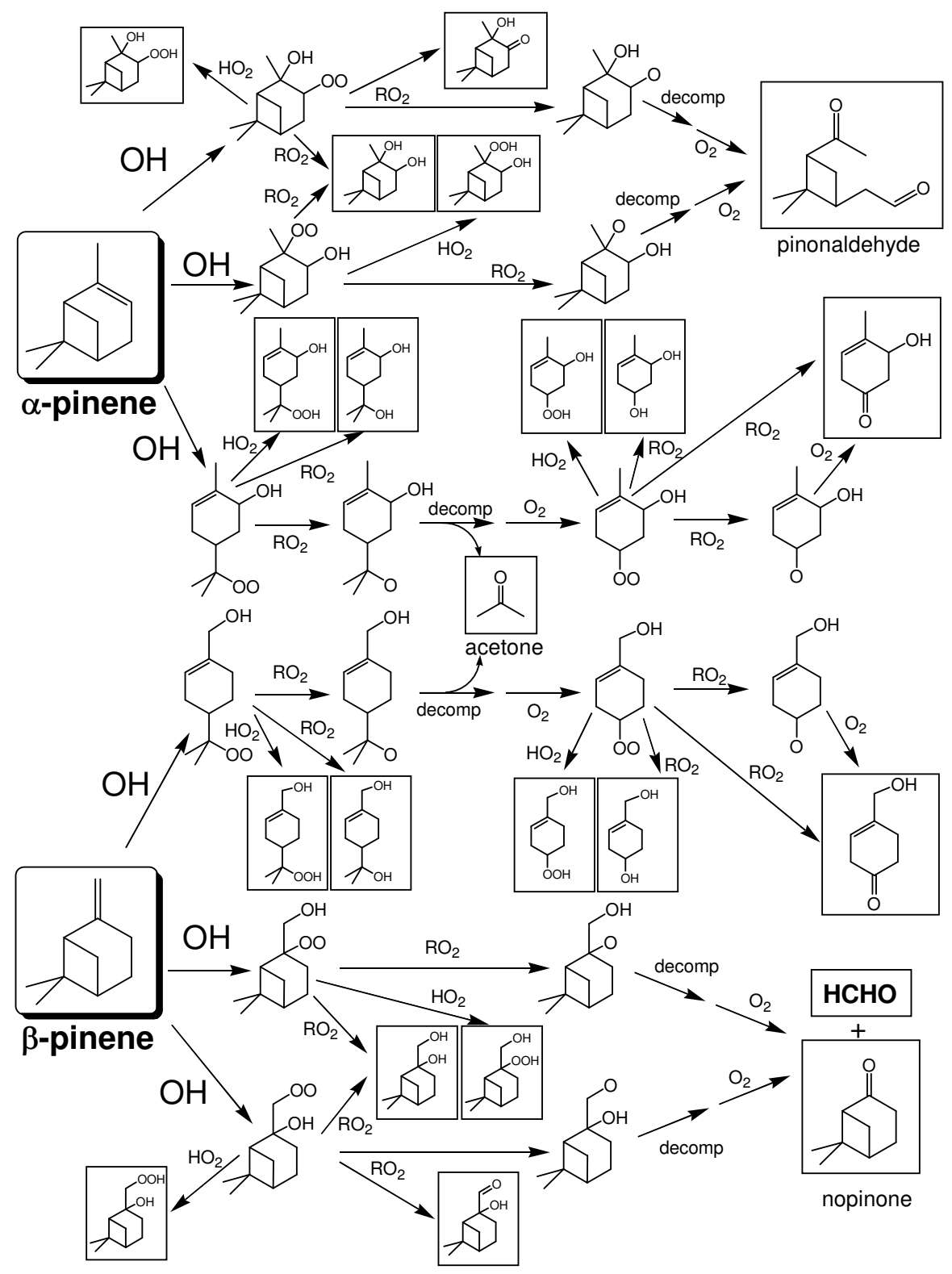

Fig. 2. Schematic representation of the major features of the $\mathrm{OH}$-initiated degradation of $\alpha$-and $\beta$-pinene in the absence of $\mathrm{NO}_{\mathrm{x}}$, as applied in the present work. Boxed species are first generation products.

vapour pressure, $p_{S}^{\circ}$, using the well-established approximation (Prausnitz, 1969),

$\ln p_{S}^{\circ}=\ln p_{L}^{\circ}-\left(\frac{\Delta \mathrm{S}_{\mathrm{fus}}\left(T_{m}\right)}{R}\left(\frac{T_{m}}{T}-1\right)\right)$

where $T_{m}$ is the melting point of the given organic species, and $\Delta \mathrm{S}_{\text {fus }}\left(T_{m}\right)$ is fusion entropy change at $\mathrm{T}_{m}$. Values of $\mathrm{T}_{m}$ were also estimated using the Joback-Reid fragmentation method (Joback and Reid, 1987), and a representative average value of $\Delta \mathrm{S}_{\text {fus }}\left(T_{m}\right)=56.5 \mathrm{~J} \mathrm{~mol}^{-1} \mathrm{~K}^{-1}$, was applied for all species (Yalkowsky, 1979; Mackay et al., 1982). Although it is recognised that this procedure only yields approximate results (particularly at temperatures well below the melting point), the resultant $298 \mathrm{~K}$ values of $p_{S}^{\circ}$ for pinonaldehyde and pinic acid (Table 1) are within a factor of ca. 5-10 of the respective reported measurements of $7.5 \times 10^{-3}$ Torr (Hallquist et al., 1997) and $3.2 \times 10^{-7}$ Torr (Bilde and Pandis, 2001), providing some support for the overall methodology adopted here.

The magnitude of $K_{p}$ determines the extent of gas-aerosol partitioning of a given species, in accordance with the following equation (Odum et al., 1996),

$\frac{C_{a}}{C_{g}}=K_{p} C_{\mathrm{om}}$, 
Table 1. Species-dependent properties calculated for selected oxidation products of $\alpha$-and $\beta$-pinene by the methods described in Sect. 2.2 . $p_{L}^{\circ}, p_{S}^{\circ}$ and $K_{p}$ values are quoted for $298 \mathrm{~K}$.

\begin{tabular}{lccccccc}
\hline & $\begin{array}{c}\mathrm{MW} \\
\mathrm{g} \mathrm{mol}^{-1}\end{array}$ & $\begin{array}{c}T_{m} \\
\mathrm{~K}\end{array}$ & $\begin{array}{c}T_{b} \\
\mathrm{~K}\end{array}$ & $\begin{array}{c}\Delta S_{\text {vap }}\left(T_{b}\right) \\
\mathrm{J} \mathrm{mol}^{-1} \mathrm{~K}^{-1}\end{array}$ & $\begin{array}{c}p_{L}^{\circ} \\
\mathrm{Torr}\end{array}$ & $\begin{array}{c}p_{S}^{\circ} \\
\text { Torr }\end{array}$ & $\begin{array}{c}K_{p}{ }^{a} \\
\mathrm{~m}^{3} \mu \mathrm{g}^{-1}\end{array}$ \\
\hline nopinone & 136 & 311 & 468 & 89.4 & $6.0 \times 10^{-1}$ & $4.5 \times 10^{-1}$ & $2.4 \times 10^{-7}$ \\
pinonaldehyde & 168 & 324 & 510 & 89.3 & $8.2 \times 10^{-2}$ & $4.6 \times 10^{-2}$ & $1.8 \times 10^{-6}$ \\
pinalic-3-acid & 170 & 423 & 563 & 89.7 & $5.9 \times 10^{-3}$ & $3.4 \times 10^{-4}$ & $2.4 \times 10^{-5}$ \\
pinonic acid & 184 & 442 & 569 & 89.8 & $4.3 \times 10^{-3}$ & $1.6 \times 10^{-4}$ & $3.4 \times 10^{-5}$ \\
pinic acid & 186 & 542 & 612 & 90.2 & $4.7 \times 10^{-4}$ & $1.8 \times 10^{-6}$ & $3.1 \times 10^{-4}$ \\
10-hydroxypinonic acid & 200 & 503 & 619 & 90.0 & $3.3 \times 10^{-4}$ & $3.1 \times 10^{-6}$ & $4.3 \times 10^{-4}$ \\
\hline
\end{tabular}

${ }^{a}$ Presented $K_{p}$ values calculated using the reference $\mathrm{MW}_{\mathrm{om}}=130 \mathrm{~g} \mathrm{~mol}^{-1} ; \mathrm{MW}_{\mathrm{om}}$ was varied during simulations on the basis of the calculated organic aerosol composition (see text).

where $C_{g}$ and $C_{a}$ are its concentrations in the gaseous and aerosol phases, respectively, and $C_{\text {om }}$ is the total concentration of condensed organic material (in $\mu \mathrm{g} \mathrm{m}^{-3}$ ). In the present work, the partitioning process was represented dynamically as a balance between absorption and desorption, using a methodology similar to that described by Kamens et al. (1999). Rate coefficients for absorption $\left(k_{\text {in }}\right)$ and desorption ( $\left.k_{\text {out }}\right)$ were assigned to the partitioning reactions for each of the identified semivolatile species, such that $k_{\text {in }} / k_{\text {out }}=K_{p}$. The rate of absorption of a given species was therefore given by the expression $k_{\mathrm{in}} C_{\mathrm{om}}$, with the desorption rate being $k_{\text {out }}$. A species and temperature-independent value of

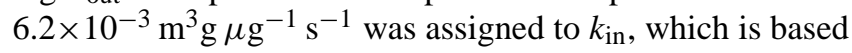
on the estimated collision rate of gaseous molecules with a monodisperse aerosol of ca. $50 \mathrm{~nm}$ diameter. At a reference temperature of $298 \mathrm{~K}$, species-dependent values of $k_{\text {out }}$ were therefore defined by $k_{\text {in }}$ and the species-dependent values of $K_{p}$. Although it is possible to calculate $K_{p}$ as a function of temperature from Eqs. (1) and (2), the temperature dependence of $k_{\text {out }}$ was represented in terms of classical evaporation by the following equation:

$k_{\text {out }}=\beta_{\text {out }} \exp \left(-E_{a} / R T\right)$

The pre-exponential factor, $\beta_{\text {out }}$, was assumed to be equivalent for all species, such that the variation of $k_{\text {out }}$ from one species to another was described in terms of speciesdependent desorption activation energies, $E_{a}$. To allow for the variation of $K_{p}$ with $\mathrm{MW}_{\mathrm{om}}$ (Eq. 1), $\beta_{\text {out }}$ was coded as follows,

$\beta_{\text {out }}=\beta_{\text {out }}^{\circ} \frac{\mathrm{MW}_{\mathrm{om}}}{\mathrm{MW}_{\mathrm{om}}^{\circ}}$,

where $\mathrm{MW}_{\mathrm{om}}^{\circ}$ is a reference molecular weight (taken to be 130) for which the species-dependent values of $K_{p}$ were defined, and $\beta_{\text {out }}^{\circ}$ is the corresponding reference value of $\beta_{\text {out }}$. In this way, the partitioning parameters responded to changes in the calculated value of $\mathrm{MW}_{\text {om }}$ during the course of a simulation. With the values of $K_{p}$ and $k_{\text {in }}$ constrained as de- scribed above, the value of $\beta_{\text {out }}^{\circ}$ and the species dependentvalues of $E_{a}$ were optimized on the basis of the observed evolution of SOA mass in a number of reported experiments at different temperatures. This is discussed further in Sect. 4.2.

The above representation of gas-aerosol partitioning was found to provide a reasonable framework for the description of SOA formation under conditions where at least several tens of $\mu \mathrm{g} \mathrm{m}^{-3}$ were present. However, based on the species generated in the chemical mechanism, and the optimized partitioning parameters, the initial stages of SOA accumulation were not well represented. As described further below (Sect. 4.2), this could be significantly improved by considering the participation of involatile dimers of bi- and multifunctional acids in the gas-to-particle conversion process. A rigorous representation would require inclusion of gas phase and aerosol phase equilibrium "permutation" reactions for each monomer-dimer combination, and gas-to-aerosol transfer reactions for each of the resultant dimers. In the present study, however, this was achieved using a simplified mechanism in which the transfer of a given acid to the aerosol phase notionally occurs by a "chaperone" mechanism involving the available "pool" of multifunctional acid species. This was represented by inclusion of a pseudo-unimolecular reaction,

$\operatorname{acid}_{(\text {gas })} \rightarrow \operatorname{acid}_{(\text {aerosol) }}$

for each of the $22 \mathrm{C}_{8}-\mathrm{C}_{10}$ bi- and multifunctional acids generated in the mechanism. Each reaction was assigned a rate coefficient $k_{5}=k_{5}^{\prime} \cdot \sum\left[\operatorname{acid}_{\left(\operatorname{gas}_{)}\right.}\right]$, where $\sum\left[\operatorname{acid}_{(\mathrm{gas})}\right]$ is the gas phase concentration sum of all the $\mathrm{C}_{8}-\mathrm{C}_{10}$ bi- and multifunctional acids, and $k_{5}^{\prime}$ is an effective bimolecular reaction rate coefficient. Although representative of a complex series of reactions, the rate coefficient, $k_{5}^{\prime}$, for the simplified reaction was represented in conventional Arrhenius form for convenience, and optimized using experimental data (see below). It is recognised that this simplified approach may not fully recreate all the subtleties of an explicit representation. However, it does introduce a gas-to-aerosol transfer process which displays an overall second order rate dependence on 
Table 2. Sources of data and conditions of experiments used to optimize and test the $\alpha$ - and $\beta$-pinene mechanism.

\begin{tabular}{|c|c|c|c|c|c|c|c|c|}
\hline Reference & Experiment $^{a}$ & {$[\text { terpene }]_{0}$} & {$[\text { ozone }]_{0}$} & $\mathrm{OH}$ scavenger & $\mathrm{T}$ & Seed aerosol & Relative humidity & SOA mass $^{b}$ \\
\hline \multicolumn{2}{|c|}{$\alpha$-pinene experiments } & $\mathrm{ppb}$ & $\mathrm{ppb}$ & & $\mathrm{K}$ & & $\%$ & $\mu \mathrm{g} \mathrm{m}^{-3}$ \\
\hline OSOA $^{c}$ & $04-10-00 \mathrm{~A}$ & 100 & 135 & none & $292-298$ & No & $0^{d}$ & 64.4 \\
\hline OSOA $^{c}$ & $05-10-00 \mathrm{~A}$ & 98 & 120 & none & 294-299 & No & 45 & 50.5 \\
\hline Yu et al. (1999a) & 6/9/98a & 59.2 & 237 & 2-butanol & 308 & Yes & 5 & 54.2 \\
\hline Yu et al. (1999a) & $6 / 9 / 98 b$ & 67.2 & 269 & 2-butanol & 308 & Yes & 5 & 65.1 \\
\hline Yu et al. (1999a) & 6/17/98a & 107.1 & 74 & 2-butanol & 306 & Yes & 5 & 38.8 \\
\hline Kamens et al. (1999) & Run A & 820 & 600 & none & 296-294 & No & $55-66$ & 2190 \\
\hline Kamens et al. (1999) & Run B & 350 & 250 & none & $296-295$ & No & $90-100$ & 504 \\
\hline Kamens et al. (1999) & Run C & 600 & 650 & none & $288-279$ & No & $62-92$ & 1860 \\
\hline Kamens and Jaoui (2001) & $12 / 9 / 96$ & 880 & 470 & none & $271-268$ & No & $32-25$ & 2650 \\
\hline Kamens and Jaoui (2001) & $8 / 12 / 99$ & 115 & 57 & none & $303-299$ & No & $\mathrm{e}$ & 65 \\
\hline \multicolumn{9}{|c|}{$\beta$-pinene experiments } \\
\hline Yu et al. (1999a) & $6 / 11 / 98 b$ & 87.9 & 352 & 2-butanol & 307 & Yes & 5 & 18.9 \\
\hline Yu et al. (1999a) & $6 / 17 / 98 b$ & 104.6 & 56 & 2-butanol & 306 & Yes & 5 & 11.2 \\
\hline Jaoui and Kamens (2003) & April 10, 2000 & 1000 & 1000 & none & $285-290$ & No & $40-50$ & 750 \\
\hline
\end{tabular}

${ }^{a}$ Experiment identified on the basis of assignment in original reference;

$b$ Based on maximum or quoted final concentration.

$c$ OSOA experiments as described by Winterhalter et al. (2003). Raw data supplied by OSOA consortium;

${ }^{d}$ Nominally dry experiment. $\mathrm{H}_{2} \mathrm{O}$ concentrations in the range $0.06-0.07 \mathrm{mBar}$. Simulations used actual data;

e $3.5 \mathrm{mBar} \mathrm{H}_{2} \mathrm{O}$ estimated by authors.

the concentration of multifunctional acid species, and which is therefore at least notionally representative of the possible effects of dimer formation.

\section{Experimental datasets}

The optimization and testing of the $\alpha$ - and $\beta$-pinene SOA formation mechanisms was carried out using a number of datasets, as summarized in Table 2 . The primary optimization was based on the results of $\alpha$-pinene ozonolysis experiments carried out as part of the EU project Origin and Formation of Secondary Organic Aerosols, OSOA, as summarized by Winterhalter et al. (2003), and on the $\alpha$-pinene studies of Yu et al. (1999a). The results of the remaining studies in Table 2 for $\alpha$-pinene (Kamens et al., 1999; Kamens and Jaoui, 2001) and $\beta$-pinene (Yu et al., 1999a; Jaoui and Kamens, 2003) were used to examine the performance of the mechanism for a wider range of reagent concentrations and experimental conditions.

\section{Results and discussion}

\subsection{Simulations of product yields}

The general performance of the $\alpha$ - and $\beta$-pinene ozonolysis mechanisms was tested by calculating the molar yields of a series of major products in the absence of an $\mathrm{OH}$ radical scavenger, and in the presence of either 2-butanol or cyclohexane to scavenge $\mathrm{OH}$. As with all simulations in the present study, this was carried out using the FACSIMILE for Windows kinetics integration package, v3 (MCPA Software). The results for a series of products, for which experimental yield data are available, are presented in Table 3. For products which are partitioned between the gaseous and condensed phases, the presented values represent the total yield. The simulated molar yields are generally consistent with reported ranges for products of both $\alpha$ - and $\beta$-pinene (e.g. Hakola et al., 1994; Alvarado et al., 1998; Christoffersen et al., 1998; Glasius et al., 1999; Yu et al., 1999a; Orlando et al., 2000), indicating that the mechanism captures the salient features. In particular, the yields of the bi- and multifunctional carboxylic acids, which are known major contributors to SOA, are broadly representative of those concluded from experimental observations (Atkinson and Arey, 2003, and references therein). As discussed above (Sect. 2.1), the absence of an $\mathrm{OH}$ scavenger allows the formation of species such as $\mathrm{C}_{10}$ diols from the $\mathrm{OH}$-initiated oxidation of the terpenes, which are not generated directly from the ozonolysis chemistry. It also results in modest changes in the overall distribution of species, depending on the extent to which they are formed from ozone and $\mathrm{OH}$ initiated oxidation.

There are also notable differences between the product distributions calculated with each of the two scavengers present. A number of products show a lower yield with 2-butanol as 
Table 3. Simulated molar yields of selected products from the ozonolysis of $\alpha$ - and $\beta$-pinene using the MCM v3 mechanism ${ }^{a}$.

\begin{tabular}{|c|c|c|c|}
\hline \multirow[b]{2}{*}{$\alpha$-pinene } & \multicolumn{2}{|c|}{ with $\mathrm{OH}$ scavenger } & \multirow[t]{2}{*}{ without $\mathrm{OH}$ scavenger } \\
\hline & cyclohexane & 2-butanol & \\
\hline pinonaldehyde & 0.175 & 0.175 & 0.289 \\
\hline pinonic acid & 0.025 & 0.025 & 0.016 \\
\hline pinalic-3-acid & 0.058 & 0.054 & 0.032 \\
\hline pinic acid & 0.032 & 0.031 & 0.019 \\
\hline 10-hydroxypinonic acid & 0.014 & 0.014 & 0.008 \\
\hline hydroxypinonaldehydes $b$ & 0.092 & 0.054 & 0.055 \\
\hline $\mathrm{C}_{10}$ diols $c$ & - & - & 0.117 \\
\hline acetone & 0.046 & 0.005 & 0.067 \\
\hline formaldehyde & 0.198 & 0.180 & 0.120 \\
\hline$\left[\mathrm{HO}_{2}\right] /\left[\mathrm{RO}_{2}\right]$ & $8.3 \times 10^{-4 d}$ & $5.5 \times 10^{-3 d}$ & $5.0 \times 10^{-4 d}$ \\
\hline \multicolumn{4}{|l|}{$\beta$-pinene } \\
\hline nopinone & 0.502 & 0.502 & 0.486 \\
\hline pinalic-3-acid & 0.077 & 0.055 & 0.058 \\
\hline pinic acid & 0.044 & 0.037 & 0.033 \\
\hline $\mathrm{C}_{10}$ diols ${ }^{c}$ & - & - & 0.049 \\
\hline acetone & 0.001 & 0.000 & 0.005 \\
\hline formaldehyde & 0.748 & 0.747 & 0.670 \\
\hline$\left[\mathrm{HO}_{2}\right] /\left[\mathrm{RO}_{2}\right]$ & $4.8 \times 10^{-3 d}$ & $4.3 \times 10^{-2 d}$ & $2.0 \times 10^{-3 d}$ \\
\hline
\end{tabular}

$a$ Yields based on simulations of mixture containing a large excess of terpene, at $298 \mathrm{~K}$ and 760 Torr and with sufficient $\mathrm{H}_{2} \mathrm{O}$ to scavenge stabilized Criegee biradicals;

${ }^{b}$ Sum of 3 isomers;

${ }^{c}$ Sum of 2 isomers. Formed from $\mathrm{OH}$ attack on $\alpha$ - and $\beta$-pinene (see Fig. 2);

${ }^{d}$ Concentration ratio.

the $\mathrm{OH}$ scavenger, compared with that calculated with cyclohexane as the scavenger. This relates to the differences in the relative concentrations of $\mathrm{RO}_{2}$ and $\mathrm{HO}_{2}$ in the two systems. As indicated above (Sect. 2.1) and in Table 3, the use of 2butanol as the scavenger leads to higher $\left[\mathrm{HO}_{2}\right] /\left[\mathrm{RO}_{2}\right]$ ratios, which allow the reactions of peroxy radicals with $\mathrm{HO}_{2}$ to compete more effectively with the peroxy radical permutation reactions involving the $\mathrm{RO}_{2}$ pool. Although this has an effect on the system as a whole, it is particularly important when the formation of a compound involves reactions of tertiary peroxy radicals, because these are well known to display a generally low reactivity with respect to self- reactions and cross reactions with other $\mathrm{RO}_{2}$ radicals (e.g. Lesclaux, 1997), and this is reflected in the assigned permutation reaction rate coefficients in MCM v3 (Jenkin et al., 1997). One such example is the formation mechanism for acetone, which invariably involves tertiary peroxy radicals of generic formula $\mathrm{R}\left(\mathrm{CH}_{3}\right)_{2} \mathrm{CO}_{2}$, as follows (Reactions $\mathrm{R} 6$ and $\mathrm{R} 7$ ):

$\mathrm{R}\left(\mathrm{CH}_{3}\right)_{2} \mathrm{CO}_{2}+\mathrm{RO}_{2} \rightarrow \mathrm{R}\left(\mathrm{CH}_{3}\right)_{2} \mathrm{CO}+\mathrm{RO}+\mathrm{O}_{2}$

$\mathrm{R}\left(\mathrm{CH}_{3}\right)_{2} \mathrm{CO}(+\mathrm{M}) \rightarrow \mathrm{R}+\mathrm{CH}_{3} \mathrm{C}(\mathrm{O}) \mathrm{CH}_{3}(+\mathrm{M})$

$\mathrm{R}\left(\mathrm{CH}_{3}\right)_{2} \mathrm{CO}_{2}+\mathrm{HO}_{2} \rightarrow \mathrm{R}\left(\mathrm{CH}_{3}\right)_{2} \mathrm{COOH}+\mathrm{O}_{2}$.
As a result, the reaction with $\mathrm{HO}_{2}$ becomes competitive for tertiary $\mathrm{RO}_{2}$ radicals, such as $\mathrm{R}\left(\mathrm{CH}_{3}\right)_{2} \mathrm{CO}_{2}$ (Reaction $\mathrm{R} 8$ ), at lower $\left[\mathrm{HO}_{2}\right] /\left[\mathrm{RO}_{2}\right]$ than it does for other $\mathrm{RO}_{2}$ classes, and inhibition of acetone formation is therefore more pronounced than that observed for other products, the formation routes of which do not involve tertiary peroxy radicals (Table 3).

The $\left[\mathrm{HO}_{2}\right] /\left[\mathrm{RO}_{2}\right]$ ratios simulated for the $\beta$-pinene ozonolysis system are generally higher than those for $\alpha$ pinene. This is because the initiation reaction partially forms the Criegee biradical $\left[\mathrm{CH}_{2} \mathrm{OO}\right]^{\ddagger}$, the decomposition of which leads to both $\mathrm{OH}$ and $\mathrm{HO}_{2}$ (e.g. Calvert et al., 2000):

$$
\begin{aligned}
& {\left[\mathrm{CH}_{2} \mathrm{OO}\right]^{*} \rightarrow \mathrm{OH}+\mathrm{HCO}} \\
& \mathrm{HCO}+\mathrm{O}_{2} \rightarrow \mathrm{HO}_{2}+\mathrm{CO} .
\end{aligned}
$$

As a result of this direct (albeit small) source of $\mathrm{HO}_{2}$, $\left[\mathrm{HO}_{2}\right] /\left[\mathrm{RO}_{2}\right]$ ratios are sufficiently elevated that reaction with $\mathrm{HO}_{2}$ is competitive for an even wider range of peroxy radicals classes. The further elevation of the ratio through use of 2-butanol as an $\mathrm{OH}$ scavenger is therefore simulated to have a notable influence on the yields of a wider array of products from $\beta$-pinene ozonolysis, including species such as pinic acid and pinalic-3-acid, (see Table 3 ). 


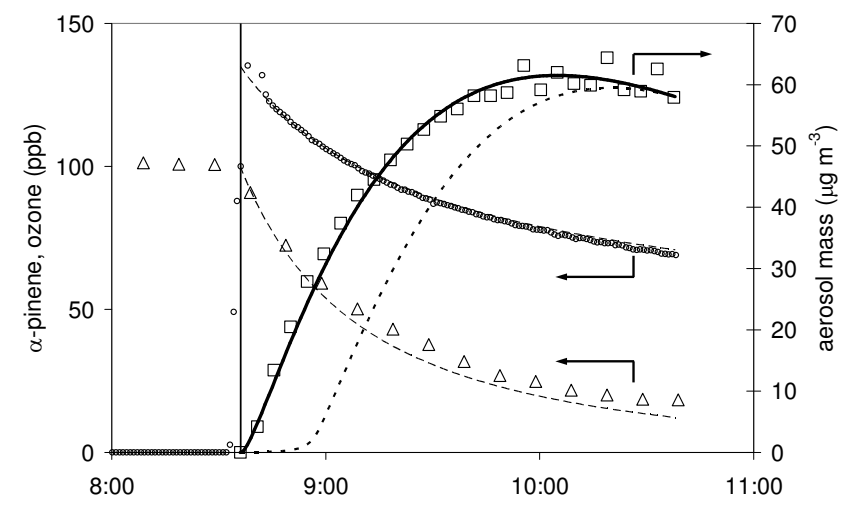

Fig. 3. Time dependence of ozone (circles), $\alpha$-pinene (triangles) and aerosol mass (squares) in OSOA experiment 04-10-00A. Lines are results of simulations using present mechanism. Dotted line represents simulated SOA accumulation using absorptive partitioning of multiple products only (scaled as described in the text). Solid line includes additional gas-to-aerosol transfer by acid chaperone mechanism.

\subsection{Simulations of SOA formation}

The mechanism was initially used to simulate the conditions of the EU OSOA and Yu et al. (1999a) $\alpha$-pinene ozonolysis experiments (see Table 2), with gas-to-aerosol conversion represented by the absorptive partitioning code described above in Sect. 2.2. Because this approach requires transfer of organic material into a pre-existing condensed organic phase, the simulations were initialized with a very small concentration $\left(1 \mathrm{ng} \mathrm{m}^{-3}\right)$ of organic aerosol. However, using the partitioning coefficients estimated by the procedure given in Sect. 2.2 (as shown for selected species in Table 1), negligible concentrations of organic aerosol were generated. A species-independent scaling factor was therefore applied to $K_{p}$ for all the partitioning species, which was manifested as a reduction in the desorption rate coefficient, $k_{\text {out }}$. Using a factor of ca. 120, it was possible to obtain a reasonable simulation of the final experimental concentrations, as shown in Figs. 3 and 4.

The magnitude of this adjustment indicates that either the key parameters involved in the estimation of $K_{p}$ values (e.g. $p_{L}^{\circ}$ ) are subject to significant systematic error, or that the aerosol formation process is not well represented simply by the absorptive partitioning of the species generated in the mechanism. Previous studies (e.g. Cocker et al., 2001; Kamens and Jaoui, 2001) have reported similar discrepancies between theoretical partitioning coefficients (based on estimated vapour pressures), and apparent partitioning coefficients (based on observed aerosol formation), and it is probable that this is due, at least in part, to the occurrence of association reactions of organics in the aerosol phase (e.g. Tobias and Ziemann, 2000; Kamens and Jaoui, 2001). For example, Tobias and Ziemann (2000) reported the formation of stable peroxyhemiacetals from the reactions of carbonyls

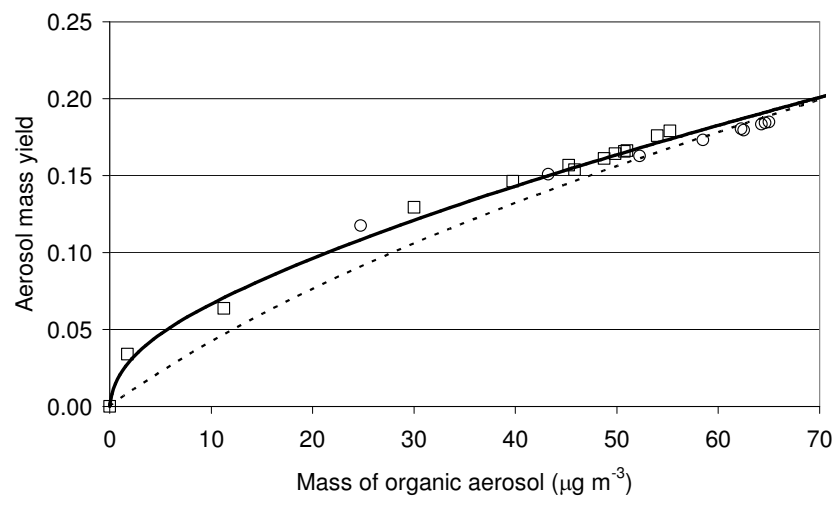

Fig. 4. Yield of organic aerosol as a function of organic aerosol mass during $\alpha$-pinene ozonolysis for the experimental conditions of Yu et al. (1999a). Points are results from two experiments of Yu et al. (1999a), as presented in Fig. 12a of their paper. Lines are results of simulations using present mechanism. Dotted line represents the optimized results of simulations using absorptive partitioning of multiple products only (scaled as described in the text). Solid line includes additional gas-to-aerosol transfer by acid chaperone mechanism.

and hydroperoxides during the ozonolysis of 1-tetradecene:

$$
\mathrm{ROOH}+\mathrm{R}^{\prime} \mathrm{C}(=\mathrm{O}) \mathrm{R}^{\prime \prime} \rightarrow \mathrm{ROOC}(\mathrm{OH}) \mathrm{R}^{\prime} \mathrm{R}^{\prime \prime}
$$

As discussed below (Sect. 4.3), the simulated composition of the organic aerosol includes important contributions from multifunctional products containing carbonyl and hydroperoxy groups, and association reactions of this and similar types to form higher molecular weight, lower volatility species would have the apparent effect of stabilising the precursor species in the condensed phase.

However, the results in Figs. 3 and 4 demonstrate that, even with such effects notionally accounted for by a scaling factor, the early stages of aerosol accumulation cannot be represented by the absorptive partitioning of the products generated in the mechanism. A similar effect was reported by Kamens and Jaoui (2001), in simulation of their lower concentration experiment "8/12/99" (see Table 2), using a kinetics code based on product absorptive partitioning. This shortcoming may be explained if species of much lower volatility are generated by the gas phase processes, which therefore have a much greater propensity to transfer to the condensed phase than those represented in the mechanism. A number of gas phase association reactions, forming high molecular weight products, have been suggested in the literature and therefore require consideration. In particular, the reactions of stabilized Criegee biradicals with carbonyls to form secondary ozonides or with acids to form $\alpha$-acyloxyalkyl hydroperoxides have been reported (e.g. Neeb et al., 1998; Tobias and Ziemann, 2001; Bonn et al., 2002), and these species certainly play an important role initiating SOA formation in some systems:

$\mathrm{RCHOO}+\mathrm{R}^{\prime} \mathrm{C}(=\mathrm{O}) \mathrm{H} \rightarrow \mathrm{RCHO}_{3} \mathrm{CHR}^{\prime}$ 


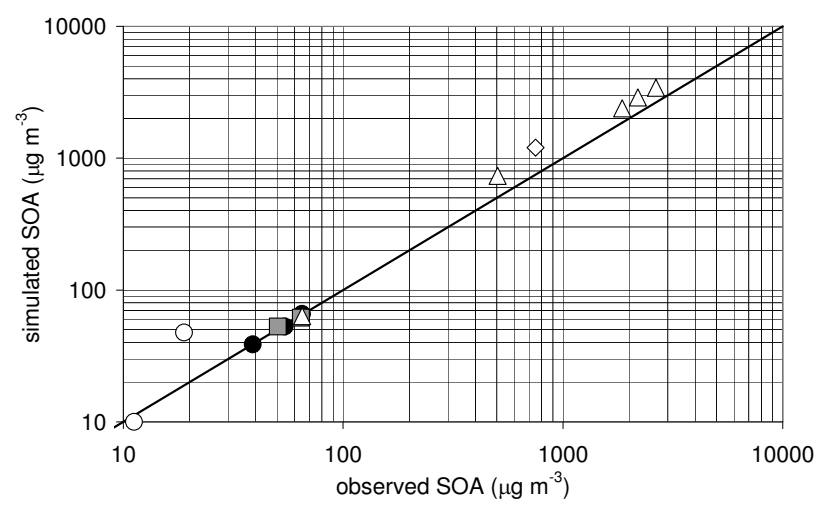

Fig. 5. Comparison of maximum or quoted final SOA mass formed in a number of reported studies of $\alpha$ - and $\beta$-pinene ozonolysis with that calculated using the present mechanism. Squares: OSOA $\alpha$ pinene; Black circles: Yu et al. (1999a) $\alpha$-pinene; Triangles: Kamens et al. (1999) and Kamens and Jaoui (2001) $\alpha$-pinene; Open circles: Yu et al. (1999a) $\beta$-pinene; Diamond: Jaoui and Kamens (2003) $\beta$-pinene.

$$
\mathrm{RCHOO}+\mathrm{R}^{\prime} \mathrm{C}(=\mathrm{O}) \mathrm{OH} \rightarrow \mathrm{RCH}(\mathrm{OOH}) \mathrm{OC}(=\mathrm{O}) \mathrm{R}^{\prime} .
$$

However, the formation of these species occurs in competition with the reaction of the Criegee biradicals with $\mathrm{H}_{2} \mathrm{O}$ (Bonn et al., 2002), which is likely to dominate under the majority of conditions employed in chamber experiments. Specifically, the results of the OSOA experiments 04-10-00A and 05-10-00A (Table 2) under nominally "dry" conditions (ca. $60 \mathrm{ppm} \mathrm{H}_{2} \mathrm{O}$ ) and at $45 \%$ relative humidity, respectively, demonstrated no significant difference in the rate of accumulation of aerosol mass, suggesting that reaction with $\mathrm{H}_{2} \mathrm{O}$ probably dominates in both experiments. Reactions of type (R12) and (R13) are therefore unlikely to account for the observed initial accumulation of aerosol in the present system.

A further possibility involves the participation of bi- and multifunctional acid dimers in the aerosol formation process. Support for this has been provided by Hoffmann et al. (1998) and Kückelmann et al. (2000), who observed the prompt formation of homomolecular and heteromolecular dimers of pinic acid, pinonic acid and other multifunctional acids from $\alpha$-pinene ozonolysis. The potential role of such species was therefore considered using the simplified "acid chaperone" representation described above in Sect. 2.2. The results of simulations using this mechanism, in addition to the absorptive partitioning mechanism, are also shown in Figs. 3 and 4 . Because the acid chaperone mechanism does not require a pre-existing condensed organic phase, these simulations were initialized with a zero concentration of organic aerosol. The operation of both mechanisms was found to allow an improved representation of the time dependence of organic aerosol formation, and the associated kinetics parameters (see Sect. 2.2) were optimized by least squares fitting to the results of the OSOA and Yu et al. (1999a) experiments. Although the chaperone mechanism does not include an ex- plicit representation of dimers in the condensed phase, their presence is also notionally accounted for by the empirical scaling factor applied to $k_{\text {out }}$, as described above.

A summary of the generic optimized parameters and species-specific parameters for selected products is given in Table 4. A comparison of the apparent partitioning coefficients, based on simulated gas and aerosol phase concentrations at the ends of the experiments, and reported partitioning coefficients, based on corresponding observations (Yu et al., 1999a; Kamens and Jaoui, 2001), indicates that the values generated by the optimized code are entirely reasonable. Logically, the temperature dependence parameters are consistent with a greater propensity for aerosol formation at lower temperatures. However, the best fit to the data sets was obtained with the absorptive partitioning mechanism possessing a comparatively weak temperature dependence, but with the "acid chaperone" mechanism being strongly temperature dependent (see Table 4, note "d"). The optimized desorption activation energies, $E_{a}$ (which describe the temperature dependence of the absorptive partitioning mechanism) are therefore substantially lower than those reported elsewhere (e.g. Kamens et al., 1999). However, the overall temperature dependence for the multifunctional acids is also influenced by the acid chaperone mechanism, such that their apparent partitioning coefficients at the ends of the experiments increase by an order of magnitude with a ten degree decrease in temperature, as shown in Table 4.

The performance of the optimized mechanism was examined for a wider range of reagent concentrations and conditions using the results of the complete series of experiments summarized in Table 2, which encompass the approximate temperature range $270-308 \mathrm{~K}$, and the formation of SOA concentrations up to $2650 \mu \mathrm{g} \mathrm{m}^{-3}$. In addition, this series includes experiments with and without $\mathrm{OH}$ scavengers, with and without inorganic seed aerosol, and covering a wide range of relative humidity. Despite these variations, the present code was found to provide an acceptable description of all the experiments. In each case, the simulated time dependence of the initial production of SOA was found to be well represented. As shown in Fig. 5, the quantity of SOA formed also compared well for a wide range of conditions, although the code tends to overestimate aerosol production by about $30 \%$ at the high end of the range.

The optimized mechanism was also used to simulate SOA formation from $\beta$-pinene ozonolysis, for a range of conditions. For example, Fig. 6 shows the simulated mass concentrations of SOA generated from $\beta$-pinene ozonolysis, compared with those generated from $\alpha$-pinene ozonolysis, in the presence of 2-butanol as an $\mathrm{OH}$ radical scavenger at $298 \mathrm{~K}$. The simulations predict that $\beta$-pinene generates smaller quantities of SOA than $\alpha$-pinene when precursor concentrations greater than about $40 \mathrm{ppb}$ are removed through reaction with ozone, which is broadly consistent with reported observations (e.g. Yu et al., 1999a; Jaoui and Kamens, 2003). Accordingly, simulations of the actual conditions in these 
Table 4. Summary of optimized partitioning parameters and comparison with the literature for selected products of $\alpha$-pinene ozonolysis.

\begin{tabular}{|c|c|c|c|c|c|}
\hline & \multirow[t]{3}{*}{$E_{a} / \mathrm{kJ} \mathrm{mol}^{-1 a}$} & \multicolumn{2}{|c|}{$K_{p}$ (apparent) $)^{b} / \mathrm{m}^{3} \mu \mathrm{g}^{-1}$} & \multicolumn{2}{|c|}{$K_{p}$ (observed $^{b} / \mathrm{m}^{3} \mu \mathrm{g}^{-1}$} \\
\hline & & \multicolumn{2}{|c|}{ Present results } & Yu et al. (1999a) & Kamens and Jaoui (2001) \\
\hline & & $298 \mathrm{~K}^{c, d}$ & $308 \mathrm{~K}^{d, e}$ & $306-308 \mathrm{~K}$ & $307 \mathrm{~K}$ \\
\hline pinonaldehyde & 7.2 & $1.8 \times 10^{-4}$ & $1.6 \times 10^{-4}$ & $1.2 \times 10^{-3}$ & $5.6 \times 10^{-5}$ \\
\hline $\mathrm{C}_{10}$ diols & $9.9-11.3$ & $(2.8-5.1) \times 10^{-4}$ & - & - & - \\
\hline hydroxypinonaldehydes & $12.3-14.8$ & $(1.3-3.9) \times 10^{-3}$ & $(1.2-3.2) \times 10^{-3}$ & $1.9 \times 10^{-2}$ & - \\
\hline pinalic-3-acid & 13.8 & $2.6 \times 10^{-2}$ & $2.2 \times 10^{-3}$ & $1.3 \times 10^{-2}$ & $2.4 \times 10^{-3}$ \\
\hline pinonic acid & 14.5 & $3.4 \times 10^{-2}$ & $2.8 \times 10^{-3}$ & $3.0 \times 10^{-2}$ & $1.3 \times 10^{-3}$ \\
\hline pinic acid & 20.0 & $3.1 \times 10^{-1}$ & $2.4 \times 10^{-2}$ & $2.8 \times 10^{-2}$ & - \\
\hline 10-hydroxypinonic acid & 20.8 & $4.4 \times 10^{-1}$ & $3.4 \times 10^{-2}$ & $4.0 \times 10^{-2}$ & - \\
\hline
\end{tabular}

${ }^{a}$ Species-independent bout optimized simultaneously. Average optimized $\beta_{\text {out }}=1.2 \times 10^{3} \mathrm{~s}^{-1}$, with actual value varying slightly with MW $\mathrm{Mm}$ (see Sect. 2.2);

${ }^{b}$ calculated from simulated or observed values of $\mathrm{C}_{\mathrm{a}}, \mathrm{C}_{\mathrm{g}}$ and $\mathrm{C}_{\mathrm{om}}$, according to Eq. (iv);

${ }^{c}$ based on simulated final concentrations under conditions of OSOA experiment 04-10-00A with absorptive partitioning and acid chaperone mechanisms operating;

$d$ acid chaperone mechanism described by optimized value of $k_{5}^{\prime}=1.5 \times 10^{-32} \exp \left(14770 / \mathrm{T}\right.$ ) $\mathrm{cm}^{3}$ molecule $\mathrm{s}^{-1}$ (see Sect. 2.2)

${ }^{e}$ based on simulated final concentrations under conditions of Yu et al. (1999a) experiment 6/9/98b with absorptive partitioning and acid chaperone mechanisms operating.

reported studies produce quantities of SOA which are in reasonable agreement with observations, as presented in Fig. 5. When terpene concentrations lower than about $40 \mathrm{ppb}$ are removed by reaction with ozone, the simulations indicate that $\alpha$ - and $\beta$-pinene generate comparable quantities of SOA (Fig. 6), with $\beta$-pinene being the slightly more efficient SOA producer.

\subsection{Simulated composition of SOA}

Figure 7 shows a comparison of the SOA compositions reported for $\alpha$-pinene ozonolysis by Winterhalter et al. (2003) and $\mathrm{Yu}$ et al. (1999a), with those simulated for the same conditions. In each case, the simulated and observed components are broadly correlated, with important contributions being made by the multifunctional acids, pinic acid, pinalic3-acid, pinonic acid and 10-hydroxypinonic acid in both the observations and the simulations. However, where comparison is possible, the simulations tend to overestimate slightly the abundance of the components observed in the OSOA experiments (Winterhalter et al., 2003), but underestimate those observed in the experiments of Yu et al. (1999a). It is therefore difficult to implement changes to the mechanism, within the framework described above, which can fully reconcile these discrepancies.

As indicated above, it is probable that association reactions occur in the condensed phase. In addition to enhancing gas-to-aerosol transfer of semivolatile species, such reactions also modify the SOA composition and therefore need to be considered in a model-observation comparison. Table 5 lists a series of other species which are simulated to

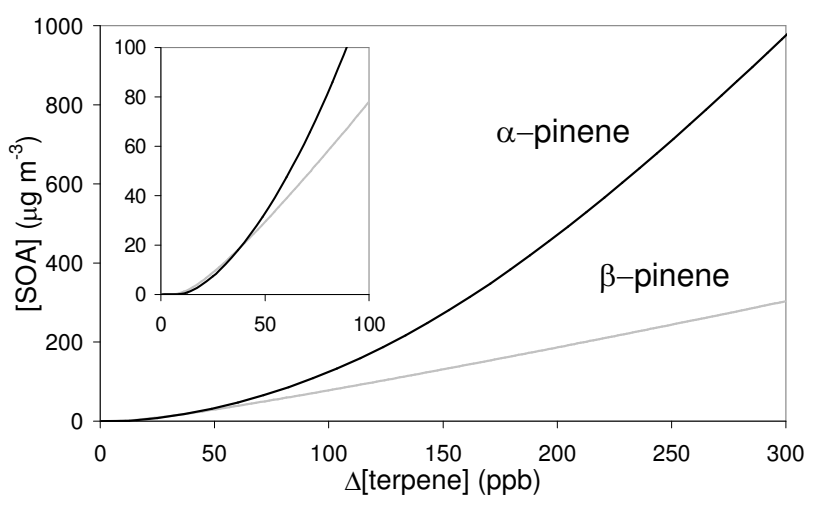

Fig. 6. Simulated mass concentration of SOA as a function of concentration of terpene removed by ozonolysis, for both $\alpha$ - and $\beta$ pinene. This illustration performed for $298 \mathrm{~K}$ with 2-butanol as an $\mathrm{OH}$ scavenger, and with sufficient $\mathrm{H}_{2} \mathrm{O}$ to scavenge stabilized Criegee biradicals.

make notable contributions to the SOA mass. These are all $\mathrm{C}_{8}-\mathrm{C}_{10}$ multifunctional compounds containing subset combinations of carbonyl (aldehyde and ketone), hydroperoxy, acid and hydroxyl functional groups. The differences in the simulated distributions under the two sets of experimental conditions mainly result from the absence of an $\mathrm{OH}$ scavenger in the OSOA studies, and the use of 2-butanol to scavenge OH in the studies of Yu et al. (1999a). However, under both sets of experimental conditions, important simulated contributions are made by species containing either carbonyl groups or hydroperoxy groups, or both. Under the OSOA experimental conditions, ca. $75 \%$ and $30 \%$ of the aerosol mass 
Table 5. Identities and simulated contributions of other significant $\operatorname{species}^{a}$ and species classes to SOA mass for the conditions of the OSOA and Yu et al. (1999a) experiments.

\begin{tabular}{|c|c|c|c|c|}
\hline \multirow[t]{2}{*}{ Species name or product class } & \multirow[t]{2}{*}{ MCM name } & \multirow[t]{2}{*}{ MW } & \multicolumn{2}{|c|}{ Contribution to SOA (mass \%) } \\
\hline & & & $\begin{array}{c}\text { OSOA } \\
\text { conditions }^{b}\end{array}$ & $\begin{array}{c}\text { Yu et al. (1999a) } \\
\text { conditions }\end{array}$ \\
\hline 3-(1-Hydroperoxy-1-methyl-ethyl)-5,6-dioxo-heptanal & $\mathrm{C} 108 \mathrm{OOH}$ & 216 & 8.8 & 17.0 \\
\hline 5-Hydroperoxy-4-hydroxymethyl-5-methyl-2-oxo-hexanoic acid & $\mathrm{C} 813 \mathrm{OOH}$ & 206 & 5.5 & 5.7 \\
\hline 1-(1-Hydroperoxy-3-hydroxymethyl-2,2-dimethyl-cyclobutyl)-2-hydroxy-ethanone & $\mathrm{C} 921 \mathrm{OOH}$ & 204 & 3.9 & 10.9 \\
\hline 3-Hydroxymethyl-2,2-dimethyl-cyclobutanecarboxylic acid & $\mathrm{C} 811 \mathrm{OH}$ & 158 & 3.8 & 1.1 \\
\hline 3-Formyl-2,2-dimethyl-cyclobutanecarboxylic acid & $\mathrm{C} 721 \mathrm{CHO}$ & 156 & 2.6 & 0.5 \\
\hline 3-(1-Hydroxy-1-methyl-ethyl)-5,6-dioxo-heptanal & $\mathrm{C} 108 \mathrm{OH}$ & 200 & 2.5 & 0.3 \\
\hline 1-(1-Hydroperoxy-3-hydroxymethyl-2,2-dimethyl-cyclobutyl)-ethanone & $\mathrm{C} 97 \mathrm{OOH}$ & 188 & 2.3 & 6.8 \\
\hline 6-Hydroperoxy-1-hydroxy-5-hydroxymethyl-6-methyl-heptane-2,3-dione & $\mathrm{C} 922 \mathrm{OOH}$ & 220 & 2.3 & 0.9 \\
\hline 6-Hydroperoxy-5-hydroxymethyl-6-methyl-heptane-2,3-dione & $\mathrm{C} 980 \mathrm{OH}$ & 204 & 2.0 & 0.8 \\
\hline 5-Hydroxy-4-hydroxymethyl-5-methyl-2-oxo-hexanoic acid & $\mathrm{C} 813 \mathrm{OH}$ & 190 & 1.8 & 0.1 \\
\hline 1-Hydroperoxy-3-hydroxymethyl-2,2-dimethyl-cyclobutanecarboxylic acid & $\mathrm{C} 812 \mathrm{OOH}$ & 190 & 1.5 & 6.8 \\
\hline 1-Hydroxy-3-hydroxymethyl-2,2-dimethyl-cyclobutanecarboxylic acid & $\mathrm{C} 812 \mathrm{OH}$ & 174 & 1.5 & 1.6 \\
\hline 2,6,6-Trimethyl-bicyclo[3.1.1]heptane-2,3-diol & $\mathrm{APINBOH}^{d}$ & 170 & 1.3 & $0.0^{d}$ \\
\hline (3-Acetyl-3-hydroperoxy-2,2-dimethyl-cyclobutyl)-acetaldehyde & $\mathrm{C} 107 \mathrm{OOH}$ & 200 & 0.9 & 11.5 \\
\hline [2,2-Dimethyl-3-(2-oxo-ethyl)-cyclobutyl]-oxo-acetaldehyde & $\mathrm{C} 109 \mathrm{CO}$ & 182 & 0.4 & 0.7 \\
\hline [3-(2-Hydroperoxy-acetyl)-2,2-dimethyl-cyclobutyl]-acetaldehyde & $\mathrm{C} 10900 \mathrm{H}$ & 200 & 0.1 & 1.8 \\
\hline Species containing carboxylic acid groups & - & - & 67.0 & 43.5 \\
\hline Species containing carbonyl groups & - & - & 74.9 & 76.4 \\
\hline Species containing aldehyde groups & - & - & 35.1 & 42.1 \\
\hline Species containing ketone groups & - & - & 58.3 & 72.0 \\
\hline Species containing hydroxy groups & - & - & 43.3 & 45.9 \\
\hline Species containing hydroperoxy groups & - & - & 28.1 & 63.3 \\
\hline
\end{tabular}

${ }^{a}$ Species are simulated to be in the top 20 contributors;

${ }^{b}$ Based on conditions of OSOA experiments 04-10-00 and 05-10-00. Listed species and those identified in Fig. 7 account for ca. $92.5 \%$ of simulated SOA mass;

${ }^{c}$ Based on conditions of Yu et al. (1999a) experiments 6/9/98a and 6/9/98b. Listed species and those identified in Fig. 7 account for ca. $97.5 \%$ of simulated SOA mass;

${ }^{d}$ APINBOH is a $\mathrm{C}_{10}$ diol generated only from the $\mathrm{OH}$-initiated chemistry, and therefore not produced when $\mathrm{OH}$ scavenger used.

is calculated to be composed of species containing carbonyl groups and hydroperoxy groups, respectively. For the Yu et al. (1999a) conditions, the corresponding contributions are calculated to be ca. $75 \%$ and $65 \%$, the much higher hydroperoxide contribution resulting from the elevated $\left[\mathrm{HO}_{2}\right] /\left[\mathrm{RO}_{2}\right]$ when 2-butanol is used as an $\mathrm{OH}$ scavenger (see Table 3). The carbonyl compounds may contain more than one carbonyl group, and respective contributions of ca. 35\% and $40 \%$ to the aerosol mass, are calculated to be made by species specifically containing aldehyde groups, under the OSOA and Yu et al. (1999a) experimental conditions.

The reactions of carbonyls with hydroperoxides to form an array of involatile, multifunctional peroxyhemiacetals (Reaction 11) are therefore clearly of potential importance. Any subsequent decomposition of the peroxyhemiacetals (within the course of the experiments or during analysis of the aerosol) may either regenerate the carbonyl and hydroperoxide precursors or possibly produce alternative products. By analogy with the mechanism of the Baeyer-Villiger oxidation of carbonyls by peracids, rearrangement and decomposition of a peroxyhemiacetal intermediate may potentially produce alcohol and ester products (from ketones), or alcohol and acid products (from aldehydes):

$\mathrm{ROOC}(\mathrm{OH}) \mathrm{R}^{\prime} \mathrm{R}^{\prime \prime} \rightarrow \mathrm{ROH}+\mathrm{R}^{\prime} \mathrm{C}(=\mathrm{O}) \mathrm{OR}^{\prime \prime}$.

The resultant oxidation of condensed phase carbonylcontaining compounds by hydroperoxide-containing compounds therefore provides possible additional mechanisms by which some of the experimentally observed SOA components (and other products) may be generated, and this may partially explain the discrepancies between the observed and simulated compositions, particularly for the conditions of the Yu et al. (1999a) experiments at elevated $\left[\mathrm{HO}_{2}\right] /\left[\mathrm{RO}_{2}\right]$. For example, this type of mechanism could result in the condensed phase oxidation of pinonaldehyde to pinonic acid, hydroxypinonaldehydes to hydroxypinonic acid isomers, and 

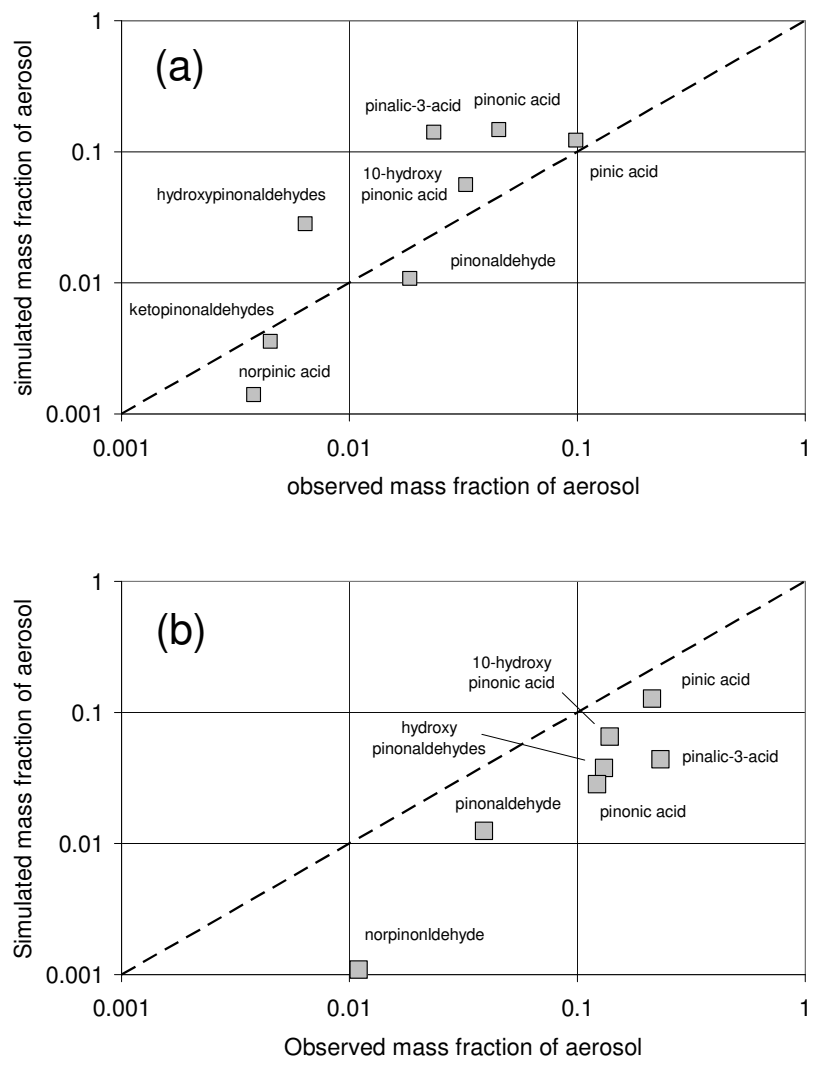

Fig. 7. Comparison of abundance of simulated and observed aerosol components: (a) Simulated abundances based on OSOA experiments 04-10-00 and 05-10-00. Observed abundances based on average of the results of these experiments and one additional experiment, as reported by Winterhalter et al. (2003); (b) Based on Yu et al. (1999a) experiments 6/9/98a and 6/9/98b. N.B. Neither experimental study distinguishes pinalic-3-acid from its isomers, pinalic4-acid and norpinonic acid. The present study only simulates notable formation of pinalic-3-acid, and this is therefore compared with the isomer total reported in the experimental studies.

pinalic-3-acid (or pinalic-4-acid) to pinic acid, with the reaction occurring at the aldehyde group in each case. Alternatively, reaction at the ketone group in ketoacids could generate acidic ester products, of the type reported by Warscheid and Hoffmann (2002).

Simulations were also performed with much higher initial $\alpha$-pinene and ozone concentrations, in the absence of an $\mathrm{OH}$ scavenger, to be more representative of the experimental conditions mainly employed by Kamens et al. (1999) and Kamens and Jaoui (2001). Important contributions from the bi- and multifunctional acids, and many of the species in Table 5, were once again apparent. However, a number of the more volatile species, which are produced in reasonably high yield by the gas phase chemistry (e.g. pinonaldehyde and the $\mathrm{C}_{10}$ diols: Table 3 ), were found to make much more significant contributions in the presence of the higher SOA mass concentrations (i.e. ca. $2500 \mu \mathrm{g} \mathrm{m}^{-3}$ ). This is fully in
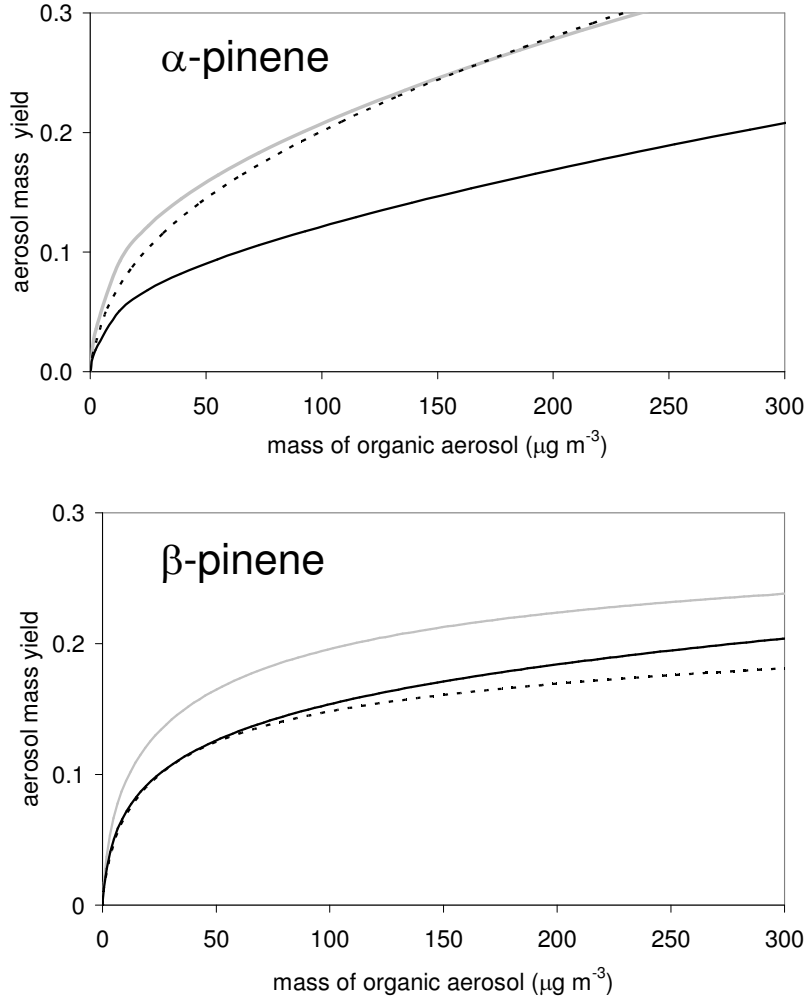

Fig. 8. Simulated variation of aerosol yield (mass concentration of aerosol per unit mass concentration of terpene removed) with mass concentration of organic aerosol at $298 \mathrm{~K}$. Simulations performed for no $\mathrm{OH}$ scavenger (solid black line), 2-butanol scavenger (broken line) and cyclohexane scavenger (grey line). Simulations assume sufficient $\mathrm{H}_{2} \mathrm{O}$ is present to scavenge stabilized Criegee biradicals.

accord with the expected effect of the absorptive partitioning mechanism under these conditions, and the results are in broad agreement with the corresponding compositional observations of Jang and Kamens (1999).

The simulated composition of SOA from the ozonolysis of $\beta$-pinene, for the conditions of the Yu et al. (1999a) experiments (see Table 2), was found to have major contributions from pinic acid and pinalic-3-acid, which collectively accounted for ca. $60 \%$ of the simulated aerosol mass. This is in reasonable agreement with that reported. Notable simulated contributions were also made by hydroperoxysubstituted carboxylic acids, such as 3-hydroperoxymethyl2,2-dimethyl-cyclobutane carboxylic acid, and the hydroxysubstituted analogues (e.g. C8110H in Table 5). Jaoui and Kamens (2003) also report significant contributions from pinic acid and pinalic-3-acid at higher reagent concentrations in the absence of an $\mathrm{OH}$ scavenger, and also from more volatile products such as nopinone and hydroxynopinone isomers. Calculations with the present mechanism under these conditions also predict larger contributions from the more volatile species in the presence of higher SOA mass concentrations. 

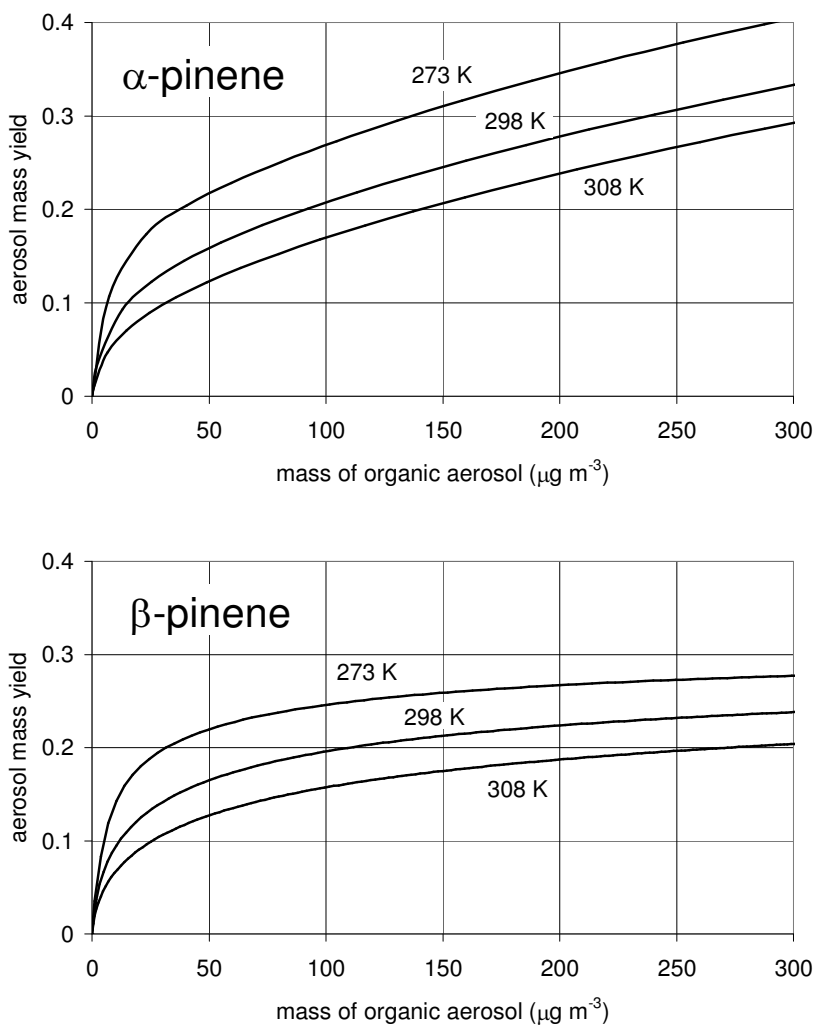

Fig. 9. Simulated variation of aerosol yield (mass concentration of aerosol per unit mass concentration of terpene removed) with mass concentration of organic aerosol, as a function of temperature. This illustration performed with cyclohexane as an $\mathrm{OH}$ scavenger, and with sufficient $\mathrm{H}_{2} \mathrm{O}$ to scavenge stabilized Criegee biradicals.

\subsection{Simulated SOA yields}

The above comparisons provide some support for the present mechanism, and its ability to recreate the quantity and composition of SOA generated from $\alpha$ - and $\beta$-pinene ozonolysis for a range of conditions. Figures 8 and 9 show corresponding calculated yields of SOA as a function of organic aerosol mass concentration. The results in Fig. 8 suggest that the SOA yield depends on whether an $\mathrm{OH}$ scavenger is present, and on its identity. In the case of $\alpha$-pinene, lower yields are calculated in the absence of an $\mathrm{OH}$ scavenger, because more than $40 \%$ of the terpene is removed by reaction with $\mathrm{OH}$, which generally produces higher volatility products than the ozonolysis reaction. The calculated yields in the presence of the scavengers are comparable, with the 2-butanol system showing slightly reduced yields compared with cyclohexane at aerosol mass concentrations below ca. $150 \mu \mathrm{g} \mathrm{m}^{-3}$. This difference relates to the influence of $\left[\mathrm{HO}_{2}\right] /\left[\mathrm{RO}_{2}\right]$ on the product distribution. Because the formation of the least volatile products generally relies on mechanisms propagated by the permutation reactions of $\mathrm{RO}_{2}$ radicals, the elevation of $\left[\mathrm{HO}_{2}\right] /\left[\mathrm{RO}_{2}\right]$ when 2-butanol is used as a scavenger leads to a slight reduction in their yields (Table 3 ), and therefore a modest reduction in the SOA yield.
The results calculated for $\beta$-pinene (Fig. 8) may be explained by the same effects, although the magnitude of these effects is different from the $\alpha$-pinene system. Once again, the absence of an $\mathrm{OH}$ scavenger has a lowering effect on the yield, but this is not as great as for $\alpha$-pinene because only about $25 \%$ of $\beta$-pinene is removed by reaction with $\mathrm{OH}$ under these conditions, owing to the smaller $\mathrm{OH}$ radical yield from the ozonolysis reaction. In the presence of cyclohexane, the calculated SOA yields are therefore greater than in the absence of an $\mathrm{OH}$ scavenger. However, the use of 2butanol as an $\mathrm{OH}$ scavenger results in a lowering of the calculated yields, such that the values are similar to or slightly lower than those in the absence of a scavenger. This is a consequence of increased $\left[\mathrm{HO}_{2}\right] /\left[\mathrm{RO}_{2}\right]$ under conditions when the system is more sensitive to the change (see Sect. 4.1). As shown in Table 3, the use of 2-butanol as a scavenger, compared with cyclohexane, has a much more marked effect on the yields of products such as pinic acid and pinalic3 -acid from $\beta$-pinene, than it does in the $\alpha$-pinene system. The current simulations therefore recreate the general effects of using different $\mathrm{OH}$ scavengers on SOA production from $\beta$-pinene ozonolysis, as reported and discussed recently by Docherty and Ziemann (2003).

Very recently, Keywood et al. (2004) have demonstrated that SOA formation during the ozonolysis of cyclohexene is also sensitive to whether cyclohexane or 2-butanol is used as an $\mathrm{OH}$ radical scavenger. In contrast to the observations of Docherty and Ziemann (2003) for $\beta$-pinene, SOA formation for cyclohexene was found to be greater in the presence of 2butanol, with the implication that larger $\left[\mathrm{HO}_{2}\right] /\left[\mathrm{RO}_{2}\right]$ ratios might generally increase SOA formation from endocyclic alkenes, and decrease it from exocyclic alkenes. Although the present calculations for $\alpha$ - and $\beta$-pinene display distinct differences in their responses to the identity of the $\mathrm{OH}$ radical scavenger (Fig. 8), the insensitivity calculated for $\alpha$-pinene also differs notably from the increased SOA formation in the presence of 2-butanol observed for cyclohexene (Keywood et al., 2004). It is not clear in advance whether a mechanism constructed for cyclohexene using the same MCM methodology as that used here for $\alpha$-pinene would yield similar calculated results. This is because there are key differences in the structural features of the two endocyclic alkenes which influence the degradation mechanism and, possibly, the response to using different $\mathrm{OH}$ scavengers. As described in more detail in the discussion paper comment (Jenkin, 2004), these relate to the fact that $\alpha$-pinene is bicyclic and contains an alkyl substitution on the double bond.

The results in Fig. 9 show the calculated temperature dependence of the SOA yield, which reflects the optimized dependences assigned to the acid chaperone and absorptive partitioning mechanisms, as described in Sect. 4.2. In both systems, therefore, the temperature dependence is strongest at small mass concentrations of organic aerosol, when SOA composition is dominated by multifunctional acids, and the acid chaperone mechanism makes an important contribution 
to calculated SOA formation. The results may therefore be compared and contrasted with the temperature-dependence calculations of Sheehan and Bowman (2001), which were carried out using purely absorptive partitioning theory.

\section{Summary and conclusions}

The formation and detailed composition of SOA from the gas phase ozonolysis of $\alpha$ - and $\beta$-pinene has been simulated using MCM v3, coupled with a representation of gasto-aerosol transfer of semivolatile and involatile oxygenated products. A kinetics representation, based on equilibrium absorptive partitioning of ca. 200 semivolatile products, has been found to provide a reasonable framework for the description of SOA accumulation under conditions where at least several tens of $\mu \mathrm{g} \mathrm{m}^{-3}$ are present, provided partitioning coefficients are increased by about two orders of magnitude over those defined on the basis of estimated vapour pressures. This may indicate a systematic overestimation of product vapour pressures, but is also likely to result from the effect of condensed phase association reactions of the partitioning products which are not explicitly represented. These may include the reactions of carbonyl-containing products with hydroperoxide-containing products to form peroxyhemiacetals, and the association of acids in the form of dimers.

The inclusion of a simplified representation of the gas phase formation of involatile homomolecular and heteromolecular dimers of 22 bi- and multifunctional carboxylic acids, and their transfer to the condensed phase, also allowed the initial stages of SOA formation to be well described. Without this additional mechanism, the simulated onset of SOA accumulation was significantly delayed, and SOA yields at low mass concentrations were substantially lower than those observed.

The composition of SOA, simulated with the optimized mechanism, successfully recreates certain features of the product distributions observed in experimental studies of $\alpha$ - and $\beta$-pinene ozonolysis. This includes major contributions from a number of multifunctional acid products, and increasing contributions from more volatile species (e.g. pinonaldehyde and nopinone) with increasing aerosol mass. However, the simulations also imply an important role for unobserved multifunctional products containing hydroperoxy groups, particularly under experimental conditions in which 2-butanol is used to scavenge $\mathrm{OH}$ radicals (i.e. when $\left[\mathrm{HO}_{2}\right] /\left[\mathrm{RO}_{2}\right]$ is elevated). Such products potentially undergo stabilizing association reactions with carbonyls to form peroxyhemiacetals. It is also possible that any subsequent decomposition of the peroxyhemiacetals (within the course of the experiments or during analysis of the aerosol) may modify SOA composition by producing alternative products such as an acid and an alcohol (if the carbonyl is an aldehyde) or an ester and an alcohol (if the carbonyl is a ketone).
Acknowledgements. The work described in this paper was funded partially by the EU project OSOA (EVK-1999-00161), and partially by the UK Natural Environment Research Council, NERC, via provision of a Senior Research Fellowship (NER/K/S/2000/00870). The collaborating partners in the OSOA project are gratefully acknowledged for giving permission to present $\alpha$-pinene ozonolysis data from the European Photoreactor, EUPHORE.

Edited by: A. Hofzumahaus

\section{References}

Alvarado, A., Tuazon, E. C., Aschmann, S. M., Atkinson, R., and Arey, J.: Products of the gas phase reactions of $\mathrm{O}\left({ }^{3} \mathrm{P}\right)$ atoms and $\mathrm{O}_{3}$ with $\alpha$-pinene and 1,2-dimethyl-1-cyclohexene, J. Geophys. Res., 103, 25 541-25 551, 1998a.

Alvarado, A., Arey, J., and Atkinson, R.: Kinetics of the gas phase reactions of $\mathrm{OH}$ and $\mathrm{NO}_{3}$ radicals and $\mathrm{O}_{3}$ with the monoterpene reaction products pinonaldehyde, caronaldehyde and sabinaketone, J. Atmos. Chem., 31, 281-297, 1998b.

Andreae, M. O. and Crutzen, P. J.: Atmospheric aerosols: biogeochemical sources and role in atmospheric chemistry, Science, 276, 1052-1058, 1997.

Aschmann, S. M., Reissel, A., Atkinson, R., and Arey, J.: Products of the gas phase reaction of the $\mathrm{OH}$ radical with $\alpha$ - and $\beta$-pinene in the presence of NO, J. Geophys. Res., 103, 25 553-25 561, 1998.

Atkinson, R., Aschmann, S. M., Arey, J., and Shorees, B.: Formation of $\mathrm{OH}$ radicals in the gas-phase reaction of $\mathrm{O}_{3}$ with a series of terpenes, J. Geophys. Res., 97, 6065-6073, 1992.

Atkinson, R. and Arey, J.: Gas-phase tropospheric chemistry of biogenic volatile organic compounds: a review, Atmos. Env., 37, Supplement No. 2, S197-S219, 2003.

Baum, E. J.: Chemical property estimation: theory and application, CRC Press, Florida, ISBN 0-87371-938-7, 1998.

Baxley, J. S. and Wells, J. R.: The hydroxyl radical reaction rate constant and atmospheric transformation products of 2-butanol and 2-pentanol, Int. J. Chem. Kin., 30, 745-752, 1998.

Bilde, M. and Pandis, S. N.: Evaporation rates and vapor pressures of individual aerosol species formed in the atmospheric oxidation of $\alpha$ - and $\beta$-pinene, Env. Sc. Tec., 35, 3344-3349, 2001.

BIOVOC: Final report on the EU project on Degradation Mechanisms of Biogenic VOC "BIOVOC", Contract reference: ENVCT95-0059: Co-ordinator J. Hjorth, JRC Ispra, 1998.

Bonn, B. and Moortgat, G. K.: New particle formation during $\alpha$ and $\beta$-pinene oxidation by $\mathrm{O}_{3}, \mathrm{OH}$ and $\mathrm{NO}_{3}$, and the influence of water vapour: particle size distribution studies, Atmos. Chem. Phys., 2, 183-196, 2002, SRef-ID: 1680-7324/acp/2002-2-183.

Bonn, B., Schuster, G., and Moortgat, G. K.: Influence of water vapour on the process of new particle formation during monoterpene ozonolysis, J. Phys. Chem. A., 106, 2869-2881, 2002.

Calogirou, A., Larsen, B. R., and Kotzias, D.: Gas-phase terpene oxidation products: a review, Atmos. Env., 33, 1423-1439, 1999.

Calvert, J. G., Atkinson, R., Kerr, J. A., Madronich, S., Moortgat, G. K., Wallington, T. J., and Yarwood, G.: The mechanisms of atmospheric oxidation of alkenes, Oxford University Press, New York, ISBN 0-19-513177-0, 2000. 
Chew, A. A. and Atkinson, R.: OH radical formation yields from the gas-phase reactions of ozone with alkenes and monoterpenes, $\mathrm{J}$. Geophys. Res., 101, 28 649-28 653, 1996.

Christoffersen, T. S., Hjorth, J., Horie, O., Jensen, N. R., Kotzias, D., Molander, L. L., Neeb, P., Ruppert, L., Winterhalter, R., Virkkula, A. Wirtz, K., and Larsen B. R.: Cis-pinic acid, a possible precursor for organic aerosol formation from ozonolysis of $\alpha$-pinene, Atmos. Env., 32, 1657-1661, 1998.

Cocker, D. R., Clegg, S. L., Flagan, R. C., and Seinfeld, J. H.: The effect of water on gas-particle partitioning of secondary organic aerosol, Part I: $\alpha$-pinene/ozone system, Atmos. Env., 35, 60496072, 2001.

Docherty, K. S. and Ziemann, P.: Effects of stabilized Criegee intermediate and $\mathrm{OH}$ radical scavengers on aerosol formation from reactions of $\beta$-pinene with $\mathrm{O}_{3}$, Aeros. Sc. Tecnol., 37, 877-891, 2003.

Fuentes, J. D., Lerdau, M., Atkinson, R., Baldocchi, D., Bottenheim, J. W., Ciccioli, P., Lamb, B., Geron, C., Gu, L., Guenther, A., Sharkey, T. D., and Stockwell, W.: Biogenic hydrocarbons in the atmospheric boundary layer: a review, Bulletin of the American Meteorological Society, 81, 1537-1575, 2000.

Geron, C., Rassmussen, R., Arnts, R. R., and Guenther, A.: A review and synthesis of monoterpene speciation from forests in the United States, Atmos. Env., 34, 1761-1781, 2000.

Glasius, M., Calogirou, A., Jensen, N. R., Hjorth, J., and Nielsen, C. J.: Kinetic study of the gas phase reactions of pinonaldehyde and structurally related compounds, Int. J. Chem. Kin., 29, 527-533, 1997.

Glasius, M., Lahaniati, M., Calogirou, A., Di Bella, D., Jensen, N. R., Hjorth, J., Kotzias, D., and Larsen, B. R.: Carboxylic acids in secondary aerosols from the oxidation of cyclic monoterpenes by ozone, Env. Sc. Tec., 34, 1001-1010, 2000.

Griffin, R. J., Cocker, D. R., Flagan, R. C., and Seinfeld, J. H.: Organic aerosol formation from oxidation of biogenic hydrocarbons, J. Geophys. Res., 104, 3555-3567, 1999.

Guenther, A., Zimmerman, P., and Wildermuth, M.: Natural volatile organic compound emission rate estimates for US woodland landscapes, Atmos. Env., 28, 1197-1210, 1994.

Hakola, H., Arey, J., Aschmann, S. M., and Atkinson, R.: Product formation from the gas phase reactions of $\mathrm{OH}$ radicals and $\mathrm{O}_{3}$ with a series of monoterpenes, J. Atmos. Chem., 18, 75-102, 1994.

Hallquist, M., Wangberg, I., and Ljungstrom, E.: Atmospheric fate of dicarbonyl products originating from $\alpha$-pinene, and $\Delta^{3}$ Carene: determination of rate of reaction with $\mathrm{OH}$ and $\mathrm{NO}_{3}$ radicals, UV absorption cross sections and vapor pressures, Env. Sc. Tec., 31, 3166-3172, 1997.

Hallquist, M., Wangberg, I., Ljungstrom, E., Barnes, I., and Becker, K. H.: Aerosol and product yields from $\mathrm{NO}_{3}$ radical initiated oxidation from selected monoterpenes, Env. Sc. Tec., 33, 553559,1999

Hoffmann, T., Odum, J. R., Bowman, F., Collins, D., Klockow, D., Flagan, R. C., and Seinfeld, J. H.: Formation of organic aerosols from the oxidation of biogenic hydrocarbons, J. Atmos. Chem., 26, 189-222, 1997.

Hoffmann, T., Bandur, R., Marggraf, U., and Linscheid, M.: Molecular composition of organic aerosols formed in the $\alpha$-pinene/ $/ \mathrm{O}_{3}$ reaction: Implications for new particle formation processes, J. Geophys. Res., 103, D19, 25 569-25 578, 1998.
Jacob, D. J. and Wofsy, S. C.: Photochemistry of biogenic emissions over the Amazon forest, J. Geophys. Res., 93, 1477-1486, 1988.

Jang, M. and Kamens, R. M.: Newly characterized products and composition of secondary aerosols from the reaction of $\alpha$-pinene with ozone, Atmos. Env., 33, 459-474, 1999.

Jaoui, M. and Kamens, R. M.: Mass balance of gaseous and particulate products from $\beta$-pinene $/ \mathrm{O}_{3} /$ air in the absence of light and $\beta$-pinene/ $\mathrm{NO}_{\mathrm{X}} /$ air in the presence of natural sunlight, J. Atmos. Chem., 45, 101-141, 2003.

Jenkin, M. E.: Interactive comment on Modelling the formation and composition of secondary organic aerosol from $\alpha$ - and $\beta$-pinene ozonolysis using MCM v3" by M. E. Jenkin., Atmos. Chem. Phys. Discuss., 4, S1493-S1502, 2004.

Jenkin, M. E., Saunders, S. M., and Pilling, M. J.: The tropospheric degradation of volatile organic compounds: A protocol for mechanism development, Atmos. Env., 31, 81-104, 1997.

Jenkin, M. E., Shallcross, D. E., and Harvey, J. N.: Development and application of a possible mechanism for the generation of cis-pinic acid from the ozonolysis of $\alpha$ - and $\beta$-pinene, Atmos. Env., 34, 2837-2850, 2000.

Joback, K. G. and Reid, R. C.: Estimation of pure-component properties from group contributions, Chemical Engineering Communications, 57, 233-243, 1987.

Kamens, R. M. and Jaoui, M.: Modeling aerosol formation from $\alpha$-pinene $+\mathrm{NO}_{\mathrm{x}}$ in the presence of natural sunlight using gasphase kinetics and gas-particle partitioning theory, Env. Sc. Tec., 35, 1394-1405, 2001.

Kamens, R. M., Jang, M., Chien, C.-J., and Leach, K.: Aerosol formation from the reaction of $\alpha$-pinene and ozone using a gasphase kinetics-aerosol partitioning model, Env. Sc. Tec., 33, 1430-1438, 1999.

Kavouras, I. G., Mihalopolous, N., and Stephanou, E. G.: Formation of atmospheric particles from organic acids produced by forests, Nature, 395, 683-686, 1998.

Kavouras, I. G., Mihalopolous, N., and Stephanou, E. G.: Secondary organic aerosol formation vs primary organic aerosol emission: in situ evidence for the chemical coupling between monoterpene acidic photooxidation products and new particle formation over forests, Env. Sc. Tec., 33, 1028-1037, 1999.

Keywood, M. D., Kroll, J. H., Varutbangkul, V., Bahreini, R., Flagan, R. C., and Seinfeld, J. H.: Secondary organic aerosol formation from cyclohexene ozonolysis: effect of $\mathrm{OH}$ scavenger and the role of radical chemistry, Env. Sc. Tec., 38, 3343-3350, 2004.

Koch, S., Winterhalter, R., Kolloff, A., Neeb, P., and Moortgat, G. K.: Organic aerosol formation processes in the photo-oxidation of VOCs. Contribution to the EUROTRAC-2 Chemical Mechanism Development (CMD) Subproject Annual Report, 1998, 189-192. Published by EUROTRAC-2 International Scientific Secretariat, GSF-Forschungszentrum fuer Umwelt und Gesundheit GmbH, Munchen, Germany, September 1999.

Kückelmann, U., Warscheid, B., and Hoffmann, T.: On-line characterization of organic aerosols formed from biogenic precursors using atmospheric pressure chemical ionization mass spectrometry, Analyt. Chem., 72, 1905-1912, 2000.

Lesclaux, R.: Combination of peroxyl radicals in the gas phase, in Peroxyl Radicals, edited by Alfassi, Z. B., John Wiley and Sons, 1997.

Mackay, D., Bobra, A. M., Chan, D. W., and Shiu, W. Y.: Vapor pressure correlations for low volatility environmental chemicals, 
Env. Sc. Tec., 16, 645-649, 1982.

Neeb., P., Horie., O., and Moortgat, G. K.: The ethene-ozone reaction in the gas phase, J. Phys. Chem. A., 102, 6778-6785, 1998.

Noziere, B., Barnes, I., and Becker, K. H.: Product study of the reactions of $\alpha$-pinene and of pinonaldehyde with $\mathrm{OH}$ radicals, $\mathrm{J}$. Geophys. Res., 104, D19, 23 645-23 656, 1999a.

Noziere, B., Spittler, M., Ruppert, L., Barnes, I., Becker, K. H., Pons, M., and Wirtz, K.: Kinetics of the reactions of pinonaldehyde with $\mathrm{OH}$ radicals and with $\mathrm{Cl}$ atoms, Int. J. Chem. Kin., 31, 4, 291-301, 1999b.

O'Dowd, C., Aalto, P., Hämeri, K., Kulmala, M., and Hoffmann, T.: Atmospheric particles from organic vapours, Nature, 416, 497498, 2002.

Odum, J. R., Hoffmann, T., Bowman, F., Collins, D., Flagan, R. C., and Seinfeld, J. H.: Gas/particle partioning and secondary organic aerosol yields, Env. Sc. Tec., 30, 2580-2585, 1996.

Orlando, J. J., Noziere, B., Tyndall, G. S., Orzechowska, G. E., Paulson, S. E., and Rudich, Y.: Product studies of the OH- and ozone-initiated oxidation of some monoterpenes, J. Geophys. Res., 105, D9, 11 561-11 572, 2000.

Pankow, J. F.: An absorption model of gas/particle partitioning involved in the formation of secondary organic aerosol, Atmos. Env., 28, 189-193, 1994.

Paulson, S. E., Chung, M., Sen, A. D., and Orzechowska, G.: Measurement of $\mathrm{OH}$ radical formation from the reaction of ozone with several biogenic alkenes, J. Geophys. Res., 103, D19, 25 533-25 559, 1998.

Prausnitz, J. M.: Molecular Thermodynamics of Fluid Phase Equilibria, Prentice-Hall, New Jersey, 1969.

Rasmussen, R. A.: What do the hydrocarbons from trees contribute to air pollution?, J. Air Poll. Cont. Assoc., 22, 537-543, 1972.

Rickard, A. R., Johnson, D., McGill, C. D., and Marston, G.: OH yields in the gas-phase reactions of ozone with alkenes, J. Phys. Chem. A., 103, 7656-7664, 1999.

Saunders, S. M., Jenkin, M. E., Derwent, R. G., and Pilling, M. J.: Protocol for the development of the Master Chemical Mechanism, MCM v3 (Part A): tropospheric degradation of nonaromatic volatile organic compounds, Atmos. Chem. Phys., 3, 161-180, 2003, SRef-ID: 1680-7324/acp/2003-3-161.

Sheehan, B. E and Bowman, F. M.: Estimated effects of temperature on secondary organic aerosol concentrations, Env. Sc. Tec., 35, 2129-2135, 2001.
Stein, S. E. and Brown, R. L.: Estimation of normal boiling points from group contributions, J. Chem. Info. Comp. Sc., 34, 581587, 1994.

Tobias, H. J. and Ziemann, P. J.: Thermal desorption mass spectrometric analysis of organic aerosol formed from reactions of 1-tetradecene and $\mathrm{O}_{3}$ in the presence of alcohols and carboxylic acids, Env. Sc. Tec., 34, 2105-2115, 2000.

Trainer, M., Williams, E. J., Parrish, D. D., Burhr, M. P., Allwine, E. J., Westberg, H. H., Fehsenfeld, F. C., and Liu, S. S.: Models and observations of the impact of natural hydrocarbons on rural ozone, Nature, 705-707, 1987.

Wangberg, I., Barnes, I., and Becker, K. H.: Product and mechanistic study of the reaction of $\mathrm{NO}_{3}$ radicals with $\alpha$-pinene, Env. Sc. Tec., 31, 2130-2135, 1997.

Warscheid, B. and Hoffmann, T.: Structural elucidation of monoterpenes oxidation products by ion trap fragmentation using on-line atmospheric pressure chemical ionization mass spectrometry in the negative ion mode, Rapid Communications in Mass Spectrometry, 15, 2259-2272, 2001.

Warscheid, B. and Hoffmann, T.: Direct analysis of highly oxidized organic aerosol constituents by on-line ion trap mass spectrometry in the negative ion mode, Rapid Communications in Mass Spectrometry, 16, 496-504, 2002.

Went, F. W.: Blue hazes in the atmosphere, Nature, 187, 641-645, 1960.

Winterhalter, R., Neeb, P., Grossmann, D., Kolloff, A., Horie, O., and Moortgat, G. K.: Products and mechanism of the gas-phase reaction of ozone with $\beta$-pinene, J. Atmos. Chem., 35, 165-197, 2000.

Winterhalter, R., Van Dingenen, R., Larsen, B. R., Jensen, N. R., and Hjorth, J.: LC-MS analysis of aerosol particles from the oxidation of $\alpha$-pinene by ozone and $\mathrm{OH}$ radicals, Atmos. Chem. Phys. Discuss., 3, 1-39, 2003 SRef-ID: 1680-7375/acpd/2003-3-1.

Yalkowski, S. H.: Estimation of entropies of fusion of organic compounds, Industrial and Engineering Chemistry Fundamentals, 18, 108-111, 1979.

Yu, J., Cocker, D. R., Griffin, R. J., Flagan, R. C., and Seinfeld, J H.: Gas-phase ozone oxidation of monoterpenes: gaseous and particulate products, J. Atmos. Chem., 34, 207-258, 1999a.

Yu, J., Griffin, R. J., Cocker, D. R., Flagan, R. C., and Seinfeld, J. H.: Observation of gaseous and particulate products of monoterpene oxidation in forest atmsopheres, Geophys. Res. Lett., 26, 1145-1148, 1999b. 